\title{
Obesity: Prevalence, Theories, Medical Consequences, Management, and Research Directions
}

\author{
Colin Wilborn, Jacqueline Beckham, Bill Campbell, Travis Harvey, Melyn Galbreath, \\ Paul La Bounty, Erika Nassar, Jennifer Wismann, and Richard Kreider. \\ Exercise and Sport Nutrition Laboratory, Baylor University, Waco, TX. Address correspondence to \\ Colin_Wilborn@baylor.edu
}

Received August 8, 2005/Accepted September 28, 2005

\begin{abstract}
Obesity and its associated disorders are a growing epidemic across the world. Many genetic, physiological, and behavioral factors play a role in the etiology of obesity. Diet and exercise are known to play a valuable role in the treatment and prevention of obesity and associated disorders such as hypertension, heart disease, and diabetes. Therefore, the purpose of this review is to examine the prevalence, etiology, consequences, and treatment of obesity. Journal of the International Society of Sports Nutrition. 2(2):4-31, 2005
\end{abstract}

Key Words: weight loss, diet, exercise, physical activity, leptin, cortisol, metabolic syndrome

\section{INTRODUCTION}

Approximately 1.2 billion people in the world are overweight and at least 300 million of them are obese. According to the World Health Organization, obesity is one of the 10 most preventable health risks. Yet, at least 300,000 deaths every year in the United States alone can be linked to obesity. Obesity is associated with disorders such as hypertension, diabetes, hypercholesterolemia, and liver disease. Obesity has been thought to simply be related to an imbalance between energy intake and expenditure. However, more recent research has suggested that genetic, physiological, and behavioral factors also play a significant role in the etiology of obesity. Thus, the management of obesity through exercise, nutrition, supplementation, and medical intervention are at the forefront of research. The purpose of this review is to examine the current literature as it pertains to the prevalence, theories, medical consequences, management, and future research directions in the study of obesity. Further, this review will provide practical recommendations in dealing with athletes and/or clients who are overweight.

\section{PREVALENCE AND SOCIETAL IMPACT OF OBESITY}

\section{Obesity Prevalence in the United States}

The height/weight index considered to be the most popular of all indices ${ }^{1}$ is the body mass index (BMI). BMI is calculated by dividing a person's weight in kilograms $(\mathrm{kg})$ by the person's height in meters squared $\left(\mathrm{m}^{2}\right)$. The World Health Organization (WHO) classifies normal weight as having a BMI (BMI) of 18.5 to $24.9 \mathrm{~kg} / \mathrm{m}^{2}$, overweight 25 to 29 $\mathrm{kg} / \mathrm{m}^{2}$, moderately obese as greater than or equal to $30 \mathrm{~kg} / \mathrm{m}^{2}$, and morbidly obese as greater than or equal to $40 \mathrm{~kg} / \mathrm{m}^{2}{ }^{2,3}$. The National Health Examination Survey (NHES) and the National Health and Nutrition Examination Surveys (NHANES) are crosssectional health examination surveys that are representative of the American population. These surveys were conducted at the time points of: 19601962 (NHES), 1971-1975 (NHANES I), 1976-1980 (NHANES II), 1988-1994 (NHANES III), and 19992000 (NHANES 1999-2000). In adults ages 20-74, these surveys reported an alarming increase in the percent of respondents who were obese (i.e., 14.6, $14.3,14.5,22.5$, and 30.4, respectively) ${ }^{4}$. Perhaps of greater concern is that the prevalence of morbidly obese Americans is estimated to have increased three-fold from 1990 to 2000 (See Figure 1) ${ }^{5}$. Overweight classification is increasing in children and adolescents as well. From the NHANES I survey to the NHANES 1999-2000 surveys, prevalence of 
obesity has increased $5.4 \%$ in $2-5$ year old, $11.3 \%$ in 6-11 year olds, and $9.4 \%$ in $12-19$ year olds ${ }^{6}$. The data from the NHANES III to the most recent NHANES 1999-2000 has shown that the overweight prevalence in all age groups has increased significantly ${ }^{6}$. These findings indicate that obesity has become a major health concern in the United States.

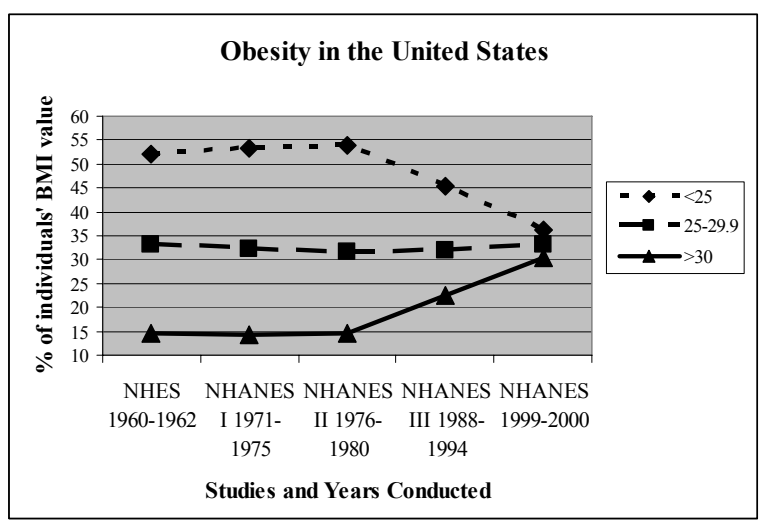

Figure 1: Prevalence of obesity in the United States as indicated by the NHES and NHANES studies. Note the progression of moderately and higher obese individuals and the diminishing of underweight and overweight individuals.

\section{Obesity Prevalence Worldwide}

The prevalence values for obesity in Europe as well as other countries with established market economies is estimated to average $15-20 \%$ of the population . In 1995, obesity in Europe was estimated to be $10-20 \%$ for men and $15-25 \%$ for women ${ }^{7}$. More recently, European obesity has been estimated as high as $22 \%$ in children, and as high as $26 \%$ in men and $31 \%$ in women. Cockram and colleagues ${ }^{8}$ reported that obesity and its related diseases such as type 2 diabetes have also been increasing in the Asia-Pacific region of the world. Obesity, especially central obesity, seems to be a primary reason for this increased rate of type 2 diabetes. Interestingly, the BMI values currently used appear underestimates risk in Asians. This might be due in part to many Asian races being more likely to develop abdominal obesity ${ }^{9}$. Therefore, the health-related consequences for Asia-Pacific individuals appear to be more intense at an absolute BMI value when compared to their European descendant counterparts. A suggested method that is possibly a more accurate assessment is a waist-to-height ratio ${ }^{10}$. This method was used by Hsieh and colleagues ${ }^{10}$ to determine the metabolic risk of Japanese men and women. They discovered that nearly all of the "overweight" subjects had high metabolic risk value, and that $45.5 \%$ of men and $28.3 \%$ of women of "normal weight" status also had high metabolic risk values when using the waist-toheight ratio method. Collectively, these findings indicate that obesity is not only a problem in the United States but is also a major health concern in Europe and other regions of the world.

\section{Societal Impact of Obesity}

The associated effect of obesity on type 2 diabetes, hypertension, coronary heart disease (CHD), gallbladder disease, osteoarthritis, and certain cancers gives rise to the increasing economic costs of obesity 11. In 1999, the cost of obesity-related health care expenditures in the United States was estimated to be approximately 24 billion dollars ${ }^{11}$. Physician office visits due to obesity increased by $88 \%$ from 1988 to $1994^{12}$. Moderately obese and severely obese individuals were estimated to have $14 \%$ and $25 \%$ more visits to their physicians, respectively, than normal weight individuals ${ }^{13}$. Visits to primary physicians have been found to be $38 \%$ higher for obese individuals than normal weight persons ${ }^{14}$. Up to 2003, the total annual medical expenditure cost for the United States has been estimated to be $5-7 \%$ of total health care costs or about 75 billion dollars a year $^{15}$.

The United States is not alone in its economic financial burden caused by obesity. Europeans have also experienced an increased prevalence of obesity and have an estimated health care cost of $1-5 \%$ of total health care expenditures . In Europe, obesityrelated health care costs are among the most costly health care determinants. In 1997, Canada was estimated to have a direct cost of obesity in excess of $\$ 1.8$ billion $^{16}$. Nearly one-third of Canadian adults have been estimated to be at increased risk of disability, disease, and premature death, due to obesity $^{16}$. In Australia, from 1981 to 2000 the prevalence of obesity has been estimated to have increased from $8.1 \%$ to $20.5 \%$, respectively ${ }^{17}$. This may place their direct health care costs and indirect costs above $\$ 1.5$ billion dollars a year. Consequently, obesity has a major health and economic cost worldwide.

\section{Obesity and Mortality Rates}

While it is clear that obesity increases risk to a number of life threatening diseases, the link to mortality is less clear. In this regard, throughout the history of medicine, the connection between obesity and mortality has been of considerable interest and debate. There are four major methodological issues to consider when attempting to draw conclusions 
from the literature in terms of the effects of obesity on mortality rates. They include the following: 1.) the effects of smoking; 2.) the effect of pre-existing disease and weight fluctuation; 3.) the effect of physical inactivity; and, 4.) the lack of precision and accuracy in the use of BMI as an estimate of adiposity ${ }^{18}$. Other potential confounding variables in associating obesity with mortality include: age, race, family history, and the influence of weight loss on mortality ${ }^{19-21}$.

Observational studies on the effects of weight loss show mortality rate decreases with obesity related comorbidities (e.g., diabetes). However, in apparently healthy overweight/obese adults, intentional weight loss seems to neither decrease nor increase mortality rate. Persons with lower levels of BMI are at a greater mortality risk than those with midrange BMI's. Some persons with low BMI are more likely to be sedentary, consume high fat foods and have lower aerobic fitness. Thin people may also be consuming inadequate amounts of certain nutrients. In addition, individuals with lower levels of BMI may also be consuming inadequate amounts of certain nutrients. According to Bray and Bouchard ${ }^{1}$ a large scale, long-term, randomized controlled clinical trial is needed to examine this relationship. The authors recommend that such a study include: 1.) a sample of persons along a broad range of BMI; 2.) serial measures of body composition; 3.) thorough and ongoing clinical evaluations of health status; 4.) use of clinically relevant markers of sub-clinical disease as outcomes in addition to mortality as an endpoint.

\section{ETIOLOGY OF OBESITY}

Historically, obesity has been thought to simply be related to an imbalance between energy intake and expenditure. However, more recent research has suggested that genetic, physiological, and behavioral factors also play a significant role in the etiology of obesity $^{22}$. The following section will describe how excess energy intake, sedentary lifestyle, and genetics collectively lead to the state of obesity.

\section{Energy Intake}

Energy is consumed in the diet through protein, carbohydrate and fat intake. In the presence of excess calories, the body will subsequently convert and store these energy nutrients as triglycerides in adipose tissue. Over time, if excess calories are consumed without a concomitant increase in energy expenditure, excess body fat will be stored which may lead to obesity. Excessive intake of energy nutrients has been reported to increase the size and number of adipocytes at various stages of the lifespan ${ }^{23}$. It has historically been thought that a calorie is a calorie and that the composition of isoenergetic diets would have no impact on weight gain or loss. However, more recent research has indicated that not all of the macronutrients contribute to obesity in an equal manner. For instance, a high fat meal that results in a positive energy balance will stimulate fat storage without a subsequent match in fat oxidation ${ }^{24,25}$. Furthermore, the deposition of excess dietary triglycerides into adipose tissue is associated with a very low metabolic cost $(0-2 \%)^{22}$ whereas the thermic effect for carbohydrate and protein is $6-8 \%$ and $25-30 \%$, respectively ${ }^{26}$. Thus, of the three macronutrients, protein requires the greatest metabolic cost to be converted to and stored as fat ${ }^{26}$.

A number of studies have examined the effects of macronutrient intake at identical energy intakes on weight loss. For example, Labayen and colleagues ${ }^{27}$ studied the effects of a high protein hypo-caloric diet versus a high carbohydrate hypo-caloric diet in terms of subsequent weight loss. The authors concluded that the replacement of some dietary carbohydrate by protein in energy restricted diets improves weight and fat losses by promoting lipid oxidation in the fasting state and sparring protein $\operatorname{loss}^{27}$. Similar results were found when obese participants consumed either an ad libitum high protein or high carbohydrate diet with fat intake kept constant in both groups (i.e., 30\% of total energy $)^{28}$. The authors found that the replacement of some dietary carbohydrate by protein in an ad libitum fat-reduced diet improves weight loss and increases the proportion of subjects achieving a clinically relevant weight loss. Other studies have reported similar results in relation to the effectiveness and safety of a high protein diet ${ }^{29-31}$.

It should be noted that in long-term weight reduction diets, it appears that both standard protein $(15 \%$ protein, 55\% carbohydrate) or high-protein (HP; 30\% protein, $40 \%$ carbohydrate) diets result in net weight loss and improvements in cardiovascular risk factors 32,33 . The type of fat in the diet has also been reported to influence body mass. For example, consumption of a diet rich in medium-chain triglycerides (MCT) results in greater loss of adipose tissue compared with long-chain triglycerides, perhaps due to increased energy expenditure and fat oxidation observed with MCT intake. Hence, MCTs may be considered as agents that aid in the prevention of obesity or potentially stimulate weight loss ${ }^{34}$. 
In addition to macronutrient influences, the volume of food intake may play a role in satiation and subsequent energy intake. It has been shown that eating low-energy-dense foods like fruits and vegetables helps sustain satiety while concurrently reducing energy intake and appears to be a more effective weight loss strategy than fat reduction and decreased portion sizes ${ }^{35}$. Fruits and vegetables are high in water and fiber, incorporating them in the diet can reduce energy density, promote satiety, and decrease energy intake ${ }^{36,37}$. Epstein and colleagues ${ }^{38}$ found that obese individuals that increased fruit and vegetable intake lost significantly more weight than those who restricted high fat/high sugar foods.

Over recent years, researchers have explored how caloric and macronutrient intake affects gene expression. When obese participants were assigned to one of two hypocaloric diets $(20-25 \%$ fat or 40 $45 \%$ fat), they lost $7 \mathrm{~kg}$ over the ten-week duration of the study. The researchers found that 10 genes were regulated by the energy restriction ${ }^{39}$. Levels of peroxisome proliferator-activated receptor gamma co-activator 1alpha mRNA were increased, while the expression of the genes encoding leptin, osteonectin, phosphodiesterase 3B, hormone-sensitive lipase, receptor A for natriuretic peptide, fatty acid translocase, lipoprotein lipase, uncoupling protein 2 and peroxisome proliferator-activated receptor gamma was decreased ${ }^{39}$. The authors concluded that energy restriction rather than the ratio of fat to carbohydrate in a low-energy diet is important in modifying the expression of genes in the human adipose tissue. It has also been shown that, a very low calorie diet (VLCD) significantly reduced adipose tissue mRNA levels of PPAR gamma and of leptin, but significantly increased TNF alpha mRNA levels ${ }^{40}$.

Twin studies are often used to control for genetic differences among the participants and give insight into the true effectiveness of the intervention being studied. For example, Faith et al. ${ }^{41}$ studied the effects of alterations in caloric intake and energy expenditure in monozygotic and dizygotic twins and reported that there may be macronutrient-specific familial influence. Also, greater-than-average caloric intake was associated with increased levels of body fat, despite likely genetic influences on both phenotypes ${ }^{41}$. In a related study, Tholin et al. ${ }^{37}$ studied genetic and environmental influences on eating behavior in a large cohort of monozygotic and dizygotic twins. The results of this investigation highlighted the importance of genetic factors in the eating behavior in young adult male twins. In addition, it has recently been reported that the increase in the prevalence of obesity has concomitantly occurred with an increase in portion sizes of foods that we consume ${ }^{35}$.

\section{Energy Expenditure}

Energy expenditure is composed of basal metabolic rate, the thermic effect of food, and physical activity. Physical activity can also be broken down into two distinct sub-classes: (1) activity-related thermogenesis (volitional exercise); and (2) nonactivity related exercise thermogenesis (consists of all activity that one performs that is not related to "sporting-like" exercise) ${ }^{42}$. Activity thermogenesis accounts for approximately $15 \%$ to $50 \%$ of total daily expenditure in the sedentary to very active populations, respectively ${ }^{43}$. It has been estimated that spontaneous minor activity performed during the day accounts for $20 \%$ of the differences of energy expenditure in a 24 hour time frame ${ }^{44}$. Equally important, Castaneda et al. ${ }^{45}$ reported that minimal amounts of spontaneous physical activity are a major predictor of accumulating fat mass during overfeeding in humans. It is also been shown in epidemiological studies that there is an inverse association between physical activity and weight ${ }^{46}$. Similarly, Meredith et al. ${ }^{47}$ also reported that there was a negative association between aerobic exercise at 65 to $80 \%$ maximal oxygen uptake and body composition. Additionally, a meta-analysis demonstrated that resistance training as well as aerobic exercise is effective in facilitating improvements in body composition, which may be due to the positive effects that resistance-training has in terms of increasing or maintaining lean mass ${ }^{48}$. Adding physical activity to promote weight loss encourages favorable changes in body composition. Sedentary lifestyle is commonly mentioned as a significant cause to the mounting prevalence of obesity. In a recent study conducted by Slentz et al. ${ }^{49}$ , researchers affirmed that those individuals who partake in a modest exercise program similar to the ones suggested by the Centers for Disease Control and the American College of Sports Medicine (e.g., at least 30 minutes of physical activity, on most days of the weeks, of moderate intensity, in one single or in multiple sessions), significant increases in health benefits can be expected. In another study ${ }^{50}$, researchers looked at the comparison of monozygotic twins in relation to lipoprotein and weight variation between vigorously active and sedentary siblings. The authors reported that vigorous exercise could possibly reduce genetic influences on body mass index. Increasing physical activity and energy 
expenditure both prevents and treats obesity, but this recommendation is often not followed. Hill and colleagues $^{43}$ reported that $22-29 \%$ of adults don't spend any time in leisure time physical activity.

\section{Possible Mechanisms}

In addition to the aforementioned causes of obesity, there are several hormones, genetic components, and secreted factors currently under investigation that have been implicated in the etiology of obesity. Some of these have an effect on long-term control of energy intake (e.g., leptin, neuropeptide Y) while others appear to have a short-term impact on energy intake (e.g., ghrelin, insulin, and cholecystokinin). The following overview discusses the role that several hormones, neuropeptides, and other factors may play in development of obesity.

Insulin. Insulin is an anabolic hormone, not only in regards to muscle, but also fat. Insulin is known to direct the storage and utilization of energy in the adipocytes $^{51}$. When an individual becomes insulin resistant, more insulin is subsequently secreted from the beta cells of the pancreas. Abdominal obesity is related to insulin resistance and type 2 diabetes ${ }^{52}$. While increased body weight moderately reduces hepatic and peripheral insulin sensitivity, central obesity causes far greater impairments ${ }^{53}$. Other hormones may play a role in the development of insulin resistance and obesity. For example, leptin and adiponectin have been reported to increase insulin sensitivity. Conversely, tumor necrosis factor-alpha (TNF- $\alpha$ ) and resistin likely facilitate insulin resistance ${ }^{54}$. Furthermore, leptin has been shown to decrease insulin secretion ${ }^{55}$. The role that insulin, insulin sensitivity, and the control of insulin levels may play in the etiology of obesity is an area needing more research.

Leptin. Leptin is a cytokine-like polypeptide produced by the adipocyte that controls food intake through the activation of hypothalamic receptors ${ }^{56}$. Leptin is produced proportionately to the adipose mass and thus informs the brain of the fat store level. Upon binding to its receptor, activation of the Janus kinase/signal transducers and activators of transcription (JAK/STAT) pathway is responsible for leptin's effects ${ }^{57}$. Once leptin binds to its receptor (OB-R) in the hypothalamic arcuate nucleus, it induces the synthesis of $\alpha$-melanocyte stimulating hormone $(\alpha-\mathrm{MSH})$ from the prohormone proopiomelanocortin (POMC) through proteolytic cleavage mediated by the enzyme pro-hormone convertase (1PC-1). Subsequently, $\alpha$-MSH binds to the melanocortin 4 receptor (MC4R) in the paraventricular nucleus which inhibits the effectors of food intake ${ }^{56}$.

When leptin is injected into leptin deficient animals, it results in decreased food intake and subsequent weight loss and the maintenance of weight loss. Obese humans do not have a deficiency of leptin, but surprisingly have higher levels of circulating leptin in the body. This would indicate that leptin deficiency is not a primary cause of obesity, but rather a decreased response to leptin. Several theories have been postulated in relation to this unresponsiveness to circulating plasma leptin levels. First, there appears to be a threshold plasma leptin concentration $(\sim 25$ $\mathrm{ng} / \mathrm{ml}$ ) above which the uptake of leptin into the hypothalamus does not increase anymore in spite of high values of leptin (i.e. leptin receptor saturation). Thus, in patients with morbid obesity, an increase in leptin production by the enlarged fat mass would be futile ${ }^{58}$. Second, there may be defect in the hypothalamic leptin receptor OB-R. Finally, there may be a defect in the leptin signaling cascade. Some of these defects may include genetic mutations in POMC, PC-1, and MC4-R (all are involved in the leptin signaling cascade described above). In reality, most obese individuals do not have a defect in the leptin receptor ${ }^{59}$. The determination of whether defects in the leptin signaling cascade plays a role in the development of obesity needs further research.

Neuropeptide $\boldsymbol{Y}$. Closely related to impaired leptin function and its effects on energy intake is the role of neuropeptide $Y$. Neuropeptide $Y$ is one of the most potent stimulators of food intake ${ }^{60}$. Leptin (when functioning properly) modulates the expression of neuropeptide $\mathrm{Y}$ that helps to control the drive to consume excess food. Neuropeptide $Y$ and leptin do not appear to be the only factors responsible for the control of energy intake. It is likely that neuropeptide $\mathrm{Y}$ and leptin interact with other regulatory peptides in a yet unexplained fashion ${ }^{22}$. As stated above, neuropeptide Y stimulates food intake. In a recent study examining the role of neuropeptides in the control of appetite, it was observed that the highest plasma neuropeptide $\mathrm{Y}$ levels were found in obese hypertensive and diabetic patients ${ }^{61}$.

Cortisol. Cortisol is a glucocorticoid known to have powerful metabolic effects. These include mobilization of fatty acids from stored triglycerides, hepatic gluconeogenesis, and proteolysis. Epel et al. ${ }^{62}$ studied fifty-nine healthy pre-menopausal women, their cortisol levels and subsequent eating 
patterns to both a session where stress was induced and a control session on various days. The study revealed that the women who had high cortisol secretions in response to the stress session ate larger quantities of food and significantly more sweet foods 62. It is commonly known that people who are suffering from Cushing syndrome have elevated levels of cortisol secretion and associated visceral or abdominal fat ${ }^{63,64}$. Therefore, it appears that an excessive amount of cortisol leads to an increase in the storage of abdominal fat. In addition, a review article by Bjorntorp et al. ${ }^{63}$ makes it clear that there is an association between hypercortisolemic states and obesity which appears to be related to a hypothalamic dysfunction. Equally important, it seems that the hypothalamic-pituitary-adrenal (HPA) axis works in concert with acute increases in insulin after feeding in both humans and rats ${ }^{65}$. This synergistic action could possibly lead to increases in visceral adipose tissue storage ${ }^{65}$. Researchers have found an association between central body fat, perceived stress and elevated cortisol levels ${ }^{63}$. However, it is still unclear whether cortisol abnormalities are a cause or merely a result of obesity.

Ghrelin. Ghrelin, a growth hormone secretagogue, is highly concentrated in the stomach. Gastric ghrelin expression and secretion increases with fasting (and hence stimulate feeding) and declines in the postprandial state ${ }^{66}$. Surprisingly, reduced plasma ghrelin concentrations have been reported in human obesity ${ }^{53}$. The effect of ghrelin on weight is probably mediated through central antagonism of leptin and other anorectic cytokines through signals delivered via vagal afferents, rather than a direct blood borne effect on the hypothalamus 67 . This action may be mediated through increased expression of hypothalamic neuropeptide $\mathrm{Y}^{67}$. In addition to stimulating feeding, ghrelin is involved in the regulation of growth hormone secretion. Further research should clarify the extent to which these actions are distinct or intrinsically related.

Norepinephrine, Serotonin, Interleukin-6 and $\boldsymbol{T N F \boldsymbol { \alpha }}$. Other biological factors have been shown to influence energy intake and possibly contribute to obesity. Norepinephrine both stimulates and decreases food intake depending on which type of receptor it interacts with. When it acts on $\alpha-1$ adrenoreceptors in the paraventricular nucleus (PVN) it decreases food intake. Conversely, when norepinephrine acts on $\alpha-2$ adrenoreceptors in the PVN it results in the stimulation of food intake ${ }^{68}$. Serotonin works in a similar fashion. Stimulation of the $5 \mathrm{HT}_{1 \mathrm{~A}}$ receptor by serotonin acutely stimulates food intake, but this response rapidly attenuates. Reduction in food intake by serotonin probably occurs by action on the $5-\mathrm{HT}_{2 \mathrm{C}}$ receptor ${ }^{68}$. Interleukin-6 (IL-6) that circulates through the blood has been reported to be correlated with BMI ${ }^{69}$. Trujillo and colleagues ${ }^{70}$ reported that adipose tissue IL-6 expression is increased in obesity and is a strong predictor of abnormalities in adipocyte and systemic metabolism. Equally important, IL-6 may modulate leptin production and lipid metabolism in human adipose tissue ${ }^{70}$. Tumor necrosis factor alpha $(\mathrm{TNF} \alpha)$ has been reported to stimulate IL-6 production from the adipose tissue P80 receptors that contribute to adipocyte differentiation and may play a role in the inhibition of leptin ${ }^{71}$. In an investigation studying obese children, $\mathrm{TNF} \alpha$ concentrations were significantly higher than in controls ${ }^{72}$.

Other Hormones Implicated in Obesity. Testosterone reduces lipoprotein lipase activity and increases lipolysis in males, but in females these effects are counteracted by estrogen ${ }^{71}$. Testosterone has also been reported to regulate leptin mRNA expression ${ }^{71}$. The growth hormone/insulin like growth factor axis (GH-IGF-1 axis) is an important regulator of body composition. Multiple GH-IGF axis defects are present in obese individuals ${ }^{1}$. Evidence suggests that growth hormone is an important hormone in lipolysis ${ }^{73}$. Not all of growth hormone's effects are mediated through IGF-1 however. Hansen ${ }^{74}$ reports that growth hormone stimulates lipolysis, protein synthesis and indirectly inhibits proteolysis through IGF-1. Another hormone that had been thought to be related to obesity is thyrotropin stimulating hormone (TSH). Iacobellis et al. ${ }^{75}$ reported that TSH and BMI were positively related and TSH has been found to be correlated with leptin adjusted for BMI. However, the interest surrounding thyroid hormones as a treatment for obesity may not be supported by research. In one study, the authors concluded that there appears to be no place for $\mathrm{T} 3$ as an adjunct to dieting, since it mostly enhances body protein loss and has only minimal effects on body fat loss ${ }^{76}$. Corticotropin-releasing hormone (CRH) may act through CRH-2 receptors to reduce food intake ${ }^{77}$. Melanocyte-stimulating hormone may be another important modulator of feeding, because it has been shown in mice that damage to the melanocortin-4 receptor in the hypothalamus leads to massive obesity 78.

Other Peptides Implicated in Obesity . The list of peptides that stimulate or suppress food intake continues to grow. Peptides that stimulate food 
intake include neuropeptide $\mathrm{Y}$ (described above), melanin-concentrating hormone $(\mathrm{MCH})$, and growth hormone releasing hormone $(\mathrm{GHRH}){ }^{79}$. The list of inhibitory peptides includes cholecystokinin (CCK), which decreases food intake centrally as well as peripherally. This was confirmed in a study conducted by Brennan and collegues ${ }^{80}$. In this study, CCK increased fullness and decreased subsequent energy intake. Lastly, enterostatin is a particularly interesting peptide because it is derived in the gastrointestinal tract and specifically reduces fat intake ${ }^{68}$.

Metabolic Syndrome. Metabolic Syndrome is characterized by a group of metabolic risk factors that include the following: central obesity (excessive fat tissue in and around the abdomen); atherogenic dyslipidemia (blood fat disorders, mainly high triglycerides and low HDL cholesterol; raised blood pressure $(130 / 85 \mathrm{mmHg}$ or higher); insulin resistance or glucose intolerance (the body can't properly use insulin or blood sugar); prothrombotic state (e.g., high fibrinogen or plasminogen activator inhibitor [-1] in the blood); and, proinflammatory state (e.g., elevated highsensitivity C-reactive protein in the blood) ${ }^{81}$. The combination of insulin resistance, abdominal obesity, dsylipidemia, and hypertension are all established risk factors for cardiovascular disease, type 2 diabetes mellitus and stroke. Insulin resistance, visceral fat, and hormones are primary pathological factors in Metabolic Syndrome. Research findings suggest a quantitative connection between cortisol secretion and metabolic syndrome ${ }^{63}$. One particularly powerful affect of cortisol is its ability to cause peripheral insulin resistance. Cortisol secretion is vulnerable to regulatory errors of the hypothalamic-pituitary-adrenal (HPA) axis. A number of factors are known to stimulate the stress centers indirectly in the metabolic syndrome. They are classified as environmental stressors, stimulant usage, and physiologic events ${ }^{81}$. Other physiologic elements that correlate to metabolic syndrome include: aging, cytokines and small baby syndrome ${ }^{1}$. Genetics play a large role in metabolic syndrome. The primary genes and pathways responsible include the aromatase gene, leptin receptor gene, proopiomelanocortin (POMC) gene, serotoninergic system, and the HPA axis genes corticotrophinreleasing hormone (CRH) and the GR gene. Our current societal environment seems to also play a role in metabolic disorder scenarios due to a competitive society, exposure to excessive energydense food, and physical inactivity.
In summary, research indicates that the etiology of obesity is multi-factorial and is evident in the abnormal levels of many biological molecules (Figure 2). Genetic, physiological, and behavioral factors all play a significant role in the etiology of obesity. While no single cause has been attributed to obesity, it is likely that each of the aforementioned theories all contribute to the state of obesity. In addition to the physiological abnormalities, there are medical consequences associated with obesity.

\section{MEDICAL CONSEQUENCES OF OBESITY}

There is little question that substantial excess adiposity increases mortality. The prevalence of overweight and obesity continues to rise and is reaching epidemic proportions in developed and developing countries. Due to the strong association of obesity and cardiovascular disease, type 2 Diabetes, and other chronic diseases, this trend suggests a substantial increase in obesity-related morbidity and mortality for the future. Public health approaches must focus on interventions that would educate the public on the dangers of poor lifestyle choices and their subsequent outcomes.

\section{Cardiovascular Disease, Coronary Heart Disease, Hypertension, and Congestive Heart Failure}

Obesity is classified as a risk factor for cardiovascular disease (CVD) because of its effects on cardiac structure. In obese and overweight individuals, the cardiac structure and function changes as a result of an increase in total plasma and blood volume. These changes occur due to an increase in blood volume, which results in increased LV filling, an increase in stroke volume (SV), and finally an increase in absolute cardiac output (Q). This increase in $\mathrm{Q}$ is solely due to a structural change, and is not influenced by heart rate (HR), as HR remains unchanged ${ }^{82}$. Although there is an increase in absolute $\mathrm{Q}$, when normalized to body surface area, Q remains unchanged. Over time, these structural changes result in the LV increases in myocardial wall stress, which then causes myocardial growth in the LV. The effects of obesity and overweight affect cardiovascular disease from several different angles, including arrhythmias, peripheral vascular disease (PVD) and stroke, sudden death, coronary heart disease (CHD) and atherosclerosis, and most predominantly hypertension and congestive heart failure (CHF).

Atherosclerosis develops through a progression from plaque formation to plaque rupture, formation of a 
thrombus, and then finally to fibrosis ${ }^{83}$. Obesity and distribution of body fat to the abdominal area have been linked to the promotion of plaque build up and atherosclerosis. There are several other risk factors for CHD that are associated with obesity, including diabetes, insulin resistance, dyslipidemia, hypertension, LV hypertrophy, endothelial dysfunction, chronic inflammation, and obstructive sleep apnea ${ }^{1}$. Despite these risk factors, there has been no establishment of a consistent relationship between obesity and CHD because of several problems with distribution of body fat, smoking status, and the use of inappropriate control populations ${ }^{84,85}$. Although obesity does not present a consistent relationship, body fat distribution has been shown to be related to CHD. Specifically, increased fat distribution in the abdomen has been shown to increase CHD regardless of body weight ${ }^{86}$, 87 .

Hypertension and CHF in obese individuals is most often directly related to LV hypertrophy. It has been noted that there is a strong association between hypertension and obesity in both genders, all age groups, and in almost all ethnic groups ${ }^{88,89}$. Fat distribution, including upper-body obesity or increased abdominal fat, serve as better predictors of hypertension than BMI alone ${ }^{90}$.

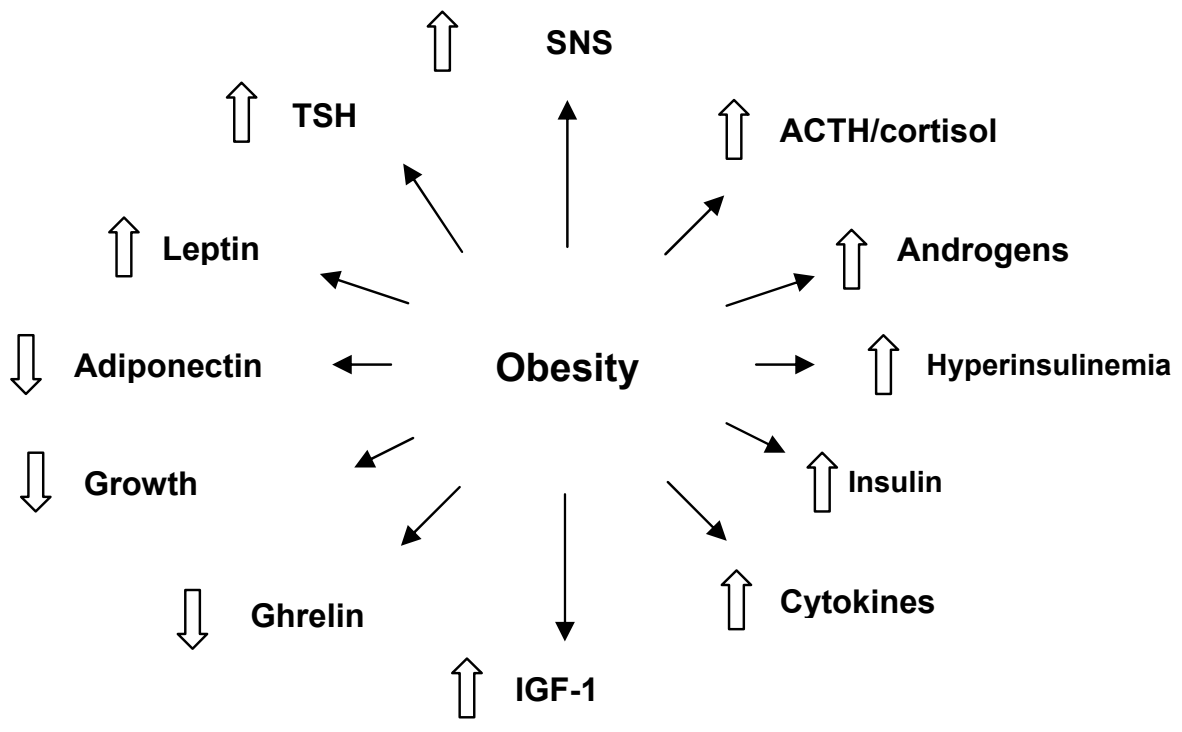

Figure 2. Adapted from Chapter 25 - Endocrine Determinants of Obesity. Handbook of Obesity - Etiology and Pathophysiology. Second Edition. Edited by George Bray and Gary Bouchard. p.663, figure 2.

There are several mechanisms in which obesity might cause hypertension. Insulin resistance ${ }^{91}$, enhanced sodium retention ${ }^{92}$, and increased activation of the sympathetic nervous system ${ }^{93}$ are all among the most researched possible mechanisms. Other mechanisms include alterations in vascular structure and function (linked with insulin resistance) ${ }^{94,95}$, alterations in ion transport, serum leptin levels ${ }^{96,97}$, and actions of the hypothalamus. Long-term obesity is associated with LV dilation and impaired systolic function with $\mathrm{CHF}$ frequently being the ultimate cause of death.

Most research indicates that weight loss in overweight and obese individuals improves CHD risk factors such as blood glucose and insulin concentrations ${ }^{98}$, blood lipids ${ }^{99}$, and blood pressure 99, 100 . Weight loss has also shown to improve cardiovascular abnormalities such as dyslipidemia, LV hypertrophy, and structural abnormalities in both adults and adolescents. Specifically, endurance training has been shown to be the most beneficial mode of exercise for decreasing cardiovascular risk factors because it enhances an increase in capillary density and muscle oxidative capacity ${ }^{101}$.

\section{Arrhythmias}

Messerli and colleagues ${ }^{102}$ found that ventricular ectopy occurred ten times more often in obese individuals than normal weight individuals. Obesity has also been shown to promote risk factors for 
arrhythmias including sleep apnea, CHD, LV hypertrophy, and autonomic imbalance ${ }^{102,103}$. The most commonly noted arrhythmias include sinus arrhythmia, premature ventricular complexes, premature atrial complexes, ventricular tachycardia, and supraventricular tachycardia ${ }^{1}$. Collectively, these findings indicate that obesity increases the risk of arrhythmia.

\section{Stroke and Peripheral Vascular Disease}

The role of obesity and overweight in stroke and PVD is based on the increased risk of ischemia and atherosclerosis ${ }^{87,104}$. However, the effect of obesity, independent of other risk factors, on stroke and PVD does not have consistent support ${ }^{104,105}$. Excess body fat is associated with the thickening of only carotid arteries, and thus, obesity alone does not appear to increase the risk for stroke or PVD ${ }^{100,106}$.

\section{Sudden Death}

Autopsy results of obese sudden death patients show that ventricular hypertrophy is the most common finding ${ }^{1}$. The three-generation Framingham Heart Study has shown that the sudden death is predictive for overweight and obese men and women based on the degree of overweight ${ }^{88}$. This factor predicts independently of other CHD risk factors. The Framingham Heart Study also showed that obese individuals with CHF have a fivefold increased risk of sudden death compared to the general population 107.

\section{Diabetes}

Approximately $85 \%$ of diabetics fall into the type 2 category and of these $70 \%$ are overweight, with a BMI of 30 or greater. It has been reported that the prevalence for type 2 diabetes is approximately 5 times higher for men and 8.3 times higher for women in obese groups compared to normal weight individuals. Furthermore, a gain in weight of 7.0$10.9 \mathrm{~kg}$ after the age of 18 years leads to a twice the risk for developing diabetes. The rate of type 2 diabetes has also risen in adolescents with physicians reporting one-third to one-half of new diabetic cases being type $2^{108}$. The diabetes epidemic is on the rise on a worldwide level especially in non-European countries. Along with a genetic disposition, sedentary lifestyle, poor nutrition, and obesity are attributed to this problem. It has been demonstrated that obesity, especially central obesity, is associated with diabetes. In the United States, the Pima Indians have the highest incidence of diabetes with Mexican
Americans having the second highest. Waist to hip ratio is often used to determine the presence of central obesity, but it appears that the waist circumference alone may be a better indicator of insulin resistance and central obesity than the waist to hip ratio. Obesity can lead to insulin resistance, which may be attributed to in part by concomitant increases in circulating free fatty acids in the blood stream. Additionally, glucose intolerance is also associated more with central obesity. It has more recently been postulated that cytokines like TNF $\alpha$, which correlate with obesity, may be a player in developing insulin resistance and Il-6 may be related to insulin sensitivity as well. Resistin and adiponectin may also pay a role in insulin resistance. It also has been established that diabetes can increase cardiac risk factors. The management of the obese diabetic patient should first include glycemic control and weight loss via caloric restriction and/or exercise with long-term maintenance goals. A loss of just 5$10 \%$ of the subject's initial body weight significantly improves the HgbA1c value, decreases blood pressure, and improves lipid profiles ${ }^{109-111}$. If weight loss is not possible through conventional means, pharmacological interventions (i.e., sibutramine, orlistat and thiazolidinediones) and surgery may be efficacious ${ }^{111}$.

\section{Gallbladder Disease}

Gallstones have a higher prevalence rate among obese populations and those losing weight. The gallstone formation requires two conditions: secretion of supersaturated bile and gallbladder stasis. Obesity directly affects bile composition and gallbladder motility. In obesity, bile is more saturated due to cholesterol hypersecretion, which leads to the impairment of gallbladder motor function ${ }^{1}$. Research has recently suggested that leptin may mediate the association between obesity and gallstones ${ }^{112}$. The incidence of gallstones in obese women has been estimated at 2.6 per 100 person-years ${ }^{113}$. The relationship between obesity and gallstones is less impressive but research has shown an increased risk of gallstones in men with increasing BMI ${ }^{114}$. Men and women undergoing bariatric surgery have as high as a $43 \%$ incidence of gallbladder disease, defined as prior cholecystectomy or gallstones. Normal pathology was more common in male patients $80 \%$ vs. $63 \%$ ) ${ }^{115}$. Ursodeoxycholic acid is the only medical therapy studied for gallstones during weight reduction ${ }^{116}$. Further research is needed in this area as well as in the area of weight reduction and the formation of gallstones. 


\section{Arthritis}

Obesity is an important risk factor for osteoarthritis and gout. These health conditions are an important area to research due to the significant morbidity and cost to the community. Musculoskeletal conditions are the cause of a larger percentage of acute and chronic disability, the most common cause of work disability. There has been a consistent relationship between osteoarthritis (OA) and obesity. Obesity is a potential modifiable risk factor for this very expensive problem. There are several possible mechanisms that explain the association between obesity and osteoarthritis. Some of these include increased joint load and indirect metabolic changes. Other metabolic conditions that may be involved with the development of osteoarthritis include: hypertension, abnormal cholesterol and blood glucose levels, and uric acid ${ }^{1}$. Recent research suggests a link between these disorders and osteoarthritis, but the data are is inconclusive at this time $^{117}$. The adjusted risk of knee osteoarthritis was increased fourfold in men with a current BMI 23 to < $25 \mathrm{~kg} / \mathrm{m}^{2}$ as compared to men with BMI $<23 \mathrm{~kg} / \mathrm{m}^{2}$. BMI at 30 years of age was similarly related to knee osteoarthritis. These researchers concluded that a moderate increase in BMI, within the normal weight range, was significantly related to knee osteoarthritis among men. Being overweight at any time was related to knee osteoarthritis ${ }^{118}$.

\section{Pregnancy and Infertility}

Obesity can affect fertility due to hormonal alterations that include: increased levels of gonadatropins and androgens which may cause anovulation, reduction in sex-hormone-binding globulin (SHBG), and increasing biologically active free androgens which are associated with anovulation. Obesity after pregnancy results in pronounced and sustained weight gain in many women and can be viewed as an example of weight cycling. The factors affecting variation in weight gain are maternal characteristics such as age, prepregnancy weight, parity (i.e., number of children borne by one woman) ethnic origin, and various aspects of socioeconomic status, drug abuse, and physical activities levels. The Stockholm Pregnancy and Weight Development Study showed 73\% of women retained $>10 \mathrm{~kg}$ of bodyweight up to one year after delivery ${ }^{119}$. In relation to infertility, a recent study concluded that infertile women with an abnormal body mass and FSH levels significantly decrease the chance of pregnancy . Infertile women are advised that their chances of assisted reproduction treatment would increase with weight loss. Researchers have also used subscapular thickness ratio (SSTR) in determining the health of offspring in the obese population. Their findings showed that maternal truncal obesity rather than thinness is associated with raised blood pressure in the offspring, and that the link may be mediated by increased cortisol secretion ${ }^{120}$.

\section{Sleep Disorders}

Global population studies suggest that the syndrome of obstructive sleep apnea, daytime sleepiness, and cardiovascular disease is present in approximately 1$4 \%$ of working men and women ${ }^{121}$. The prevalence rate is higher in minority populations and children with tonsilar hypertrophy. However, one of the bestcharacterized associations are between obesity and Obstructive Sleep Apnea (OSA). Weight gain and loss can affect the severity of this disorder. A weight gain of as little as $10 \%$ has predicted a six-fold increase in the odds of developing moderate to severe sleep-disordered breathing. A loss of $10 \%$ body weight predicted a $26 \%$ decrease in the apneahypopnea index ${ }^{122}$. Approximately $10-15 \%$ of morbidly obese patients may develop a disorder of the respiratory control system manifested by $\mathrm{CO}_{2}$ retention during wakefulness. This disorder is called obesity-hypoventilation syndrome (OHS). The exact mechanism of this disorder has yet to be explained. Aside from the obesity link, other potential explanations for this disorder include: genetic variations in ventilatory responses, interactions between the metabolic effects of obesity and respiratory control, and/or effects of comorbid cardiovascular or metabolic events also linked to obesity acting on respiratory control ${ }^{123}$. The current management strategies for OSA and OHS include weight loss through diet and exercise, anorexiant drugs, and surgically induced weight loss. The current adjunct treatments to weight loss include: noninvasive ventilation referred to as continuous positive airway pressure (CPAP), pharmacological treatment of daytime symptoms of drowsiness, tracheotomy, supplemental oxygen and treatment of coexisting pathology such as congestive heart failure ${ }^{121}$. Current research in sleep disorders is elucidating the association the role sleep plays in energy homeostasis. Researchers have analyzed associations between sleep duration and leptin and sympathovagal balance, cortisol, TSH, glucose, and insulin. The findings support that sleep modulates a major component of the neuroendocrine control of appetite 124. Another study looked at sleep deprivation and its association with hyperphagia. These scientists 
concluded that short sleep deprivation in young, healthy males was associated with decreased leptin levels and increased ghrelin levels, with subsequent increased hunger and appetite ${ }^{124}$.

\section{Quality of Life}

The health consequences and psychosocial problems associated with obesity often have an adverse effect on quality of life. The consequences of these comorbidities and conditions obviously increase the likelihood of higher rates of disability in this group of people. There is a complex relationship between obesity and disability. Sedentary lifestyle contributes to obesity and obesity exacerbates disability ${ }^{125}$. Limitations in everyday functioning of overweight and obese people are the consequence of comorbidities (e.g., peripheral vascular complications and end organ diabetic diseases). The leading cause of disability is impairment of the musculoskeletal system caused by excessive weight (e.g., chronic low back and lower extremity pain). Morbidly obese people have also been shown to have a lower quality of life. The Gastrointestinal Quality of Life Index (GIQLI) test was issued to determine the quality of life in morbidly obese patients. These patients have a poorer quality of life due to the presence of digestive symptoms as well as issues surrounding their emotional, physical, and social status ${ }^{126}$.

\section{BEHAVIORAL AND MEDICAL MANAGEMENT OF OBESITY}

\section{Behavior Management Models}

The energy imbalance leading to overweight and obesity is usually caused by behaviors that lead to increased food intake or decreased energy expenditure ${ }^{127}$. Behavioral modification is the application of learning theory to obesity treatment and has been a standard therapeutic strategy in the treatment of obesity for both adults and children for the last 25 years ${ }^{68}$. Behavior modification is recommended as one of the first approaches to obesity treatment but if it is not successful, medical treatments such as pharmacological or surgical treatments used in conjunction with behavior modification may be necessary.

Behavioral intervention is usually made by a psychologist, behavioral therapist, dietician, or exercise physiologist and treatment encourages individuals to make healthier lifestyle choices by including dimensions of increasing physical activity and modifying eating habits ${ }^{127}$. There are many models for behavior modification including operant conditioning, Pavlovian conditioning, psychoanalysis, cognitive behavioral therapy, and the transtheoretical approach. The most successful models include self-monitoring and stimulus control. The operant conditioning model includes recording behavior related to activity and food intake, which includes dimensions of mood and context. Good behavior is rewarded to increase the frequency of desired behavior ${ }^{68}$. Strategies emphasize making small, but sustainable changes ${ }^{127}$. Pavlovian or classical conditioning emphasizes changing association patterns, between two stimuli ${ }^{68}$. Refer to table 1 for definitions related to behavioral management techniques related to obesity.

In a statistical analysis of the records of a commercial, noncommercial, and medical weightreducing organizations, researchers indicated that reducing caloric intake, aided by financial incentives and supportive group pressures, is suggested as the basis for weight loss success in commercial weightreducing organizations ${ }^{128}$. It should be noted that between 1999-2000 and 2001-2002, there were no significant changes among adults in the prevalence of overweight, obesity, or extreme obesity, or among children aged 6-19 years in the prevalence of at risk for overweight ${ }^{129}$.Thus, it seems that preventive measures have been somewhat successful.

A multidisciplinary weight management program based on the Transtheoretical Model, focusing on a healthy lifestyle rather than weight loss, was applied in a 6-month clinic-based weight management program. The study included 144 overweight and obese adults. The first 3 months of the program included intense intervention twice weekly for two hours followed by 3 months of reduced clinical contact. Subjects experienced significant decreases in weight, percentage body fat, BMI, total cholesterol, LDL-C, total caloric intake, and the percentage of energy intake from dietary fat as well as a significant increase in $\mathrm{VO} 2 \max (\mathrm{P}<0.05)$ at 3 months. Changes were maintained at 6 months, with further improvement in weight, total cholesterol, and LDL-C ${ }^{130}$. Also, cognitive-behavioral treatment can be used to help overweight adolescents become more assertive in coping with the social stigma of being overweight, enhance their self-esteem, and reduce their dissatisfaction with body image regardless of weight loss ${ }^{131}$. Overviews of behavioral and medical approaches in the management of obesity are included in the following section. 
Table 1. Definitions of behavioral management of obesity techniques

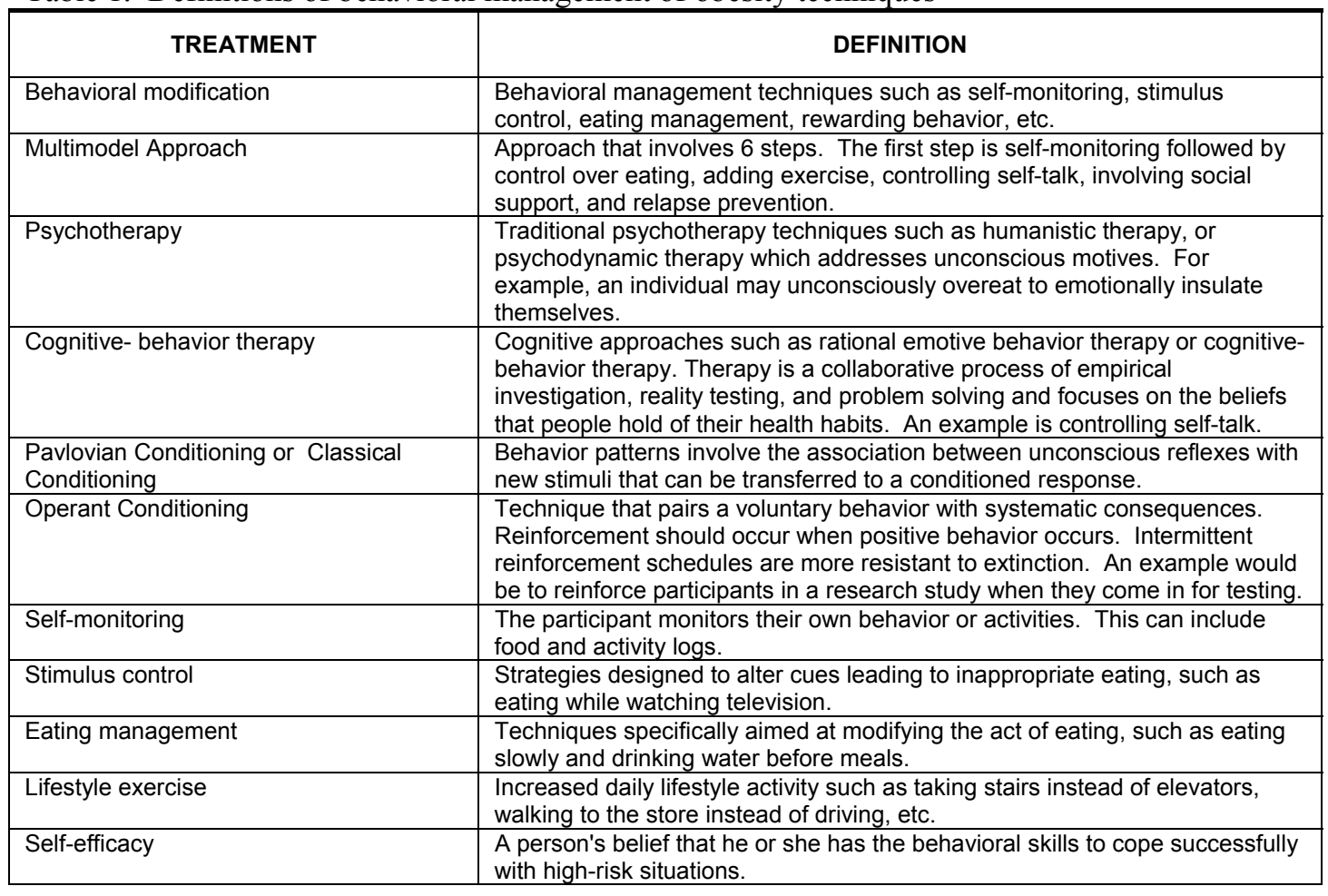

\section{Behavioral Modification of Food Intake}

Behavioral interventions designed to promote dietary change include the following: medical assessment, assessment of diet history, assessment of readiness, establishment of dietary goals, selfmonitoring, stimulus control training, training in problem solving, relapse prevention training, enlistment of social support, nutrition education, dietary therapy, and ongoing support to maintain progress ${ }^{131}$. Examples include regular pattern of meals including breakfast, controlled portion size, elimination of second helpings, elimination of high calorie drinks and snacks, decreased frequency of eating out, and eating meals with family members at a slow pace of eating. Food should never be used as a reward ${ }^{127}$. The suggestion to change dietary habits is considered behavioral modification ${ }^{132}$.

\section{Dietary Intervention}

In addition to these behavioral techniques, many diets are available. The three largest nonmedical commercial programs in the United States are Weight Watchers, Jenny Craig, and LA Weight Loss ${ }^{133}$. However, LA Weight loss does not have any reported research. The following overviews the reported efficacy of some common diets studied purported to promote weight loss.
American Heart Association. The American Heart Association ${ }^{108}$ has offered the following dietary guideline:

1. Total fat intake should be less than $30 \%$ of energy

2. Saturated fat intake should be less than $10 \%$ of total energy

3. Polyunsaturated fat intake should be no more than $10 \%$ of total energy

4. Monounsaturated fat intake should make up the rest of total fat intake, about $10 \%$ to $15 \%$ of total energy

5. Cholesterol intake should be no more than $300 \mathrm{mg} / \mathrm{d}$

6. Sodium intake should be no more than

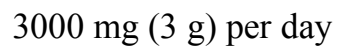

In addition, the AHA dietary guidelines include the following recommendations for food selection:

1. No more than 5-8 teaspoons of fats and oils per day, including the fats used in cooking and baking and in salad dressings and spreads

2. Six ounces or less of lean meat, fish, or skinless poultry

3. No more than three or four egg yolks per week 
4. Two to four servings of nonfat or low-fat milk and dairy products per day

5. Five or more servings of fruits and vegetables per day

6. Six or more servings of breads, cereals, rice, pasta, other grains, and starchy vegetables per day

Weight Watchers. Weight Watchers was founded in 1961 by Jean Nidtech. There have been three randomized controlled trials investigating its effectiveness. Individuals responding $(\mathrm{n}=985)$ to newspaper advertisements in two metropolitan areas were assigned to 4 weeks of either the Weight Watchers program or to a Self-Help condition. Weight loss, psychological vitality, and eating behavior were evaluated before and after a four week intervention. Results indicated that Weight Watchers participants showed greater improvements than SelfHelp participants did on all measures and weight losses averaged 1.87 and $0.77 \mathrm{~kg}$ respectively. The outcomes shown by Weight Watchers participants on measures of vitality and eating behavior were still evident when extent of weight loss was controlled across different sites, incomes, and levels of obesity 134 .

A 2-year, multicenter randomized clinical trial with clinic visits at 12, 26, 52, 78, and 104 weeks was conducted at six academic research centers in the United States between January 1998 and January 2001. Participants included overweight and obese men $(n=65)$ and women $(n=358)$ with BMI 27-40 aged 18 to 65 years. Random assignment to either a self-help program $(n=212)$ consisting of two 20 minute counseling sessions with a nutritionist and provision of self-help resources or to Weight Watchers $(n=211)$ consisting of a food plan, an activity plan, and a cognitive restructuring behavior modification plan, delivered at weekly meetings. Weight change was the primary outcome measure. Secondary outcomes included waist circumference, BMI, blood pressure, serum lipids, glucose, and insulin levels ${ }^{10}$.

Changes in serum homocysteine levels measured in a subsample of participants during the first 12 weeks. Results were reported after 26 weeks. Participants in Weight Watchers had greater decreases in body weight [mean ( \pm SD) $-4.8 \pm 5.6 \mathrm{vs}-1.4 \pm 4.7 \mathrm{~kg}$ ] and BMI $(-1.7 \pm 1.9$ vs $-0.5 \pm 1.6 \mathrm{~kg} / \mathrm{m}(2)$, both $\mathrm{P}<0.001)$ compared with those in the self-help program. Among subjects measured at week 26, mean waist circumference $(-4.3 \pm 10.5$ vs $-0.7 \pm 12.7 \mathrm{~cm})$ and fat mass $(-3.8 \pm 7.0$ vs $-1.5 \pm 7.6 \mathrm{~kg}$, both $\mathrm{P}<0.05)$ also decreased more among subjects in Weight Watchers. Mean serum homocysteine levels improved in Weight Watchers compared with self-help $(-0.5 \pm 1.3$ vs $0.9 \pm 1.8$ microM, $\mathrm{P}<0.05)$, indicating that for managing moderately overweight patients Weight Watchers is more effective than brief counseling and self-help ${ }^{135}$.

At 2 years, 150 participants (71\%) in Weight Watchers and $159(75 \%)$ in the self-help group completed the study. In the intent-to-treat analysis, mean (SD) weight loss of participants in the commercial group was greater than in the self-help group at 1 year $(-4.3 \pm 6.1 \mathrm{~kg}$ vs $-1.3 \pm 6.1 \mathrm{~kg}$, respectively; $\mathrm{P}<.001)$ and at 2 years $(-2.9 \pm 6.5 \mathrm{~kg}$ vs $0.2 \pm 6.5 \mathrm{~kg}$, respectively; $\mathrm{P}<.0001)$. Waist circumference $(\mathrm{P}=0.003)$ and BMI $(\mathrm{P}<0.001)$ decreased more in the commercial group. Changes in blood pressure, lipids, glucose, and insulin levels were related to changes in weight in both groups, but between-group differences in biological parameters were mainly nonsignificant by the second year. Authors concluded that structured commercial weight loss programs provided modest weight loss, but more than self-help programs ${ }^{10}$.

Weight loss maintenance among participants in Weight Watchers who had reached their goal weights 1-5 years previously were studied in a national sample $(n=1002)$. Participants were surveyed by phone to obtain demographic and weight-related information. An over sample $(n=258)$ was recruited and weighed in person to develop a correction factor for self-reported weights in the national sample. Results indicated that weight regain from one to 5 years following weight loss ranged between 31.5 and $76.5 \%$. At 5 years, $19.4 \%$ were within $5 \mathrm{lb}$ of goal weight, $42.6 \%$ maintained a loss of $5 \%$ or more, $18.8 \%$ maintained a loss of $10 \%$ or more, and $70.3 \%$ were below their initial weight. The authors concluded the long-term prognosis for weight maintenance among individuals who reach goal weight in Weight Watchers is better than that suggested by existing research ${ }^{134}$.

Jenny Craig. The Jenny Craig weight loss program was founded by Sid and Jenny Craig in Australia in 1983 and the first Jenny Craig opened in the United States in $1985^{136}$. The program requires a client to purchase the company's prepackaged meals as well as an initiation fee- ${ }^{133}$. In addition to the meals, the program consists of one weekly session with a trained consultant. The consultant is responsible for advising participants regarding their choice of prepared foods. The choice of foods 
includes 70 different selections. The consultant is also available for telephone advice ${ }^{136}$.

In the one published study, 517 clients attending Jenny Craig were surveyed by mail approximately 1 year post treatment regarding their current weight status. Of the 267 participants who responded to the mailed survey, it was found that $82 \%$ remained within $10 \%$ of their post treatment weights at the time of the follow-up. Researchers concluded that the high relapse rates typical for this mode of treatment may be an artifact of premature treatment cessation and further investigation is merited ${ }^{137}$.

Indeed, although commercial weight loss programs provide weight loss services with benefits of experience, planned menus, and psychological support; limitations are costs related to initiation fees and additional purchases such as vitamins.

Atkins. The Atkins low-carbohydrate diet has reigned as the high protein diet of choice for the last 30 years. The diet includes a elimination of carbohydrates of less than 20 grams per day and does not limit the intake of fat and animal protein. The diet was a radical departure from accepted nutritional principles of the time ${ }^{136}$. Dr Atkins responded to critics that the diet was deliberately unbalanced to counteract the metabolic imbalance that caused people to get fat ${ }^{138}$.

In 2002 E. Westman ${ }^{139}$ of Duke University, in a study funded by Dr Atkins's Research Foundation, published a 6-month study of 51 people placed on the Atkins diet $(<25 \mathrm{~g} / \mathrm{d})$, with no limit on caloric intake 136. They also received nutritional supplementation and recommendations about exercise, and attended group meetings at a research clinic. The outcomes were body weight, BMI, percentage of body fat (estimated by skinfold thickness), serum chemistry and lipid values, 24-hour urine measurements, and subjective adverse effects. Forty-one $(80 \%)$ of the 51 subjects attended visits through 6 months. In these subjects, the mean ( \pm SD) body weight decreased $10.3 \% \pm 5.9 \%(\mathrm{P}<0.001)$ from baseline to 6 months (body weight reduction of $9.0 \pm 5.3 \mathrm{~kg}$ and BMI

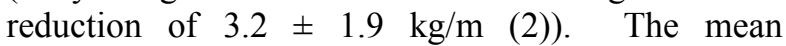
percentage of body weight that was fat decreased $2.9 \% \pm 3.2 \%$ from baseline to 6 months $(\mathrm{P}<0.001)$. The mean serum bicarbonate level decreased $2 \pm 2.4$ $\mathrm{mmol} / \mathrm{L}(\mathrm{P}<0.001)$ and blood urea nitrogen level increased $2 \pm 4 \mathrm{mg} / \mathrm{dL}(\mathrm{p}<0.001)$. Serum total cholesterol level decreased $11 \pm 26 \mathrm{mg} / \mathrm{dL}(\mathrm{p}=$ 0.006 ), low-density lipoprotein cholesterol level decreased $10 \pm 25 \mathrm{mg} / \mathrm{dL}(\mathrm{p}=0.01)$, triglyceride level decreased $56 \pm 45 \mathrm{mg} / \mathrm{dL}(\mathrm{p}<0.001)$, high- density lipoprotein (HDL) cholesterol level increased $10 \pm 8 \mathrm{mg} / \mathrm{dL}(\mathrm{p}<0.001)$, and the cholesterol/HDL cholesterol ratio decreased $0.9 \pm 0.6$ units $(\mathrm{p}<0.001)$. There were no serious adverse effects, but the possibility of adverse effects in the 10 subjects who did not adhere to the program cannot be eliminated. A control group was not included but the researchers concluded that a very low carbohydrate diet program led to sustained weight loss during a 6-month period 139 . Researchers have studied the effects of isocaloric, energy-restricted very low-carbohydrate ketogenic (VLCK) and low-fat (LF) diets (-500 kcal/day) on weight loss, body composition, trunk fat mass, and REE in overweight/obese men and women in a randomized, balanced, two diet period clinical intervention study. The goal of the VLCK diet was to decrease carbohydrate levels below $10 \%$ of energy intake and induce ketosis. The LF diet has similar goals to national recommendations (60\%carbohydrate: $25 \%$ fat: $15 \%$ ). Participants included 15 healthy, overweight/obese men (mean \pm s.e.m.: age $33.2 \pm 2.9 \mathrm{y}$, body mass $109.1 \pm 4.6 \mathrm{~kg}$, BMI $34.1 \pm 1.1 \mathrm{~kg} / \mathrm{m}^{2}$ ) and 13 premenopausal women (age $34.0 \pm 2.4$ y, body mass $76.3 \pm 3.6 \mathrm{~kg}$, BMI 29.6 $\pm 1.1 \mathrm{~kg} / \mathrm{m}^{2}$ ). Measurements of weight loss, body composition, trunk fat (by dual-energy X-ray absorptiometry), and resting energy expenditure (REE) were determined at baseline and after each diet intervention. Results indicated that the nutrient intakes from food records during the VLCK $(9 \%$ carbohydrate: $63 \%$ fat: $28 \%$ protein) and the LF $(\sim 58: 22: 20 \%)$ were significantly different. Dietary energy was $1855 \mathrm{kcal} /$ day in the VLCK group compared to $1562 \mathrm{kcal} /$ day in the LF group. The VLCK diet was advantageous over a LF diet for weight loss, total fat loss, and trunk fat loss. Absolute REE (kcal/day) was decreased with both diets but REE expressed relative to body mass $(\mathrm{kcal} / \mathrm{kg}$ ) was better maintained on the VLCK diet for men only. Individual responses show that the majority of men and women experience greater weight and fat loss on a VLCK than a LF diet. Researchers concluded that the preferential loss of fat in the trunk region with a VLCK diet is novel and potentially clinically significant but requires further validation ${ }^{140}$.

In addidtion, high protein diets have been studied in adolescents. Researchers evaluated the efficacy and metabolic impact of a high-protein, lowcarbohydrate, low-fat ketogenic diet (K diet) in the treatment of six morbidly obese adolescents (aged $12-15$ ) with initial weights of $>200 \%$ of ideal body weight. The average weight was $147.8 \mathrm{~kg}$ (range, $120.6-198.6 \mathrm{~kg}$ ) with average BMI of $50.9 \mathrm{~kg} / \mathrm{m}^{2}$ 
$\left(39.8-63.0 \mathrm{~kg} / \mathrm{m}^{2}\right)$. The intervention of the $\mathrm{K}$ diet was eight weeks. Daily intake consisted of 650 to 725 calories, with substantial protein $(80-100 \mathrm{~g})$. The diet was very low in carbohydrates $(25 \mathrm{~g})$ and fat $(25 \mathrm{~g})$. This was followed by 12 weeks of the $\mathrm{K}$ diet plus two carbohydrates $(30 \mathrm{~g})$ per meal $(\mathrm{K}+2$ diet $)$. Anthropometric data, blood, and urine were collected at enrollment, during week 1 , and at 4-week intervals throughout the course of the study. REE was measured by indirect calorimetry. Body composition was estimated using dual-energy x-ray absorptiometry, bioelectrical impedance analysis, and urinary creatinine excretion at enrollment and on completion of each phase of the diet. Nocturnal polysomnography and multiple sleep latency testing were conducted at baseline and repeated after an average weight loss of $18.7 \mathrm{~kg}$ to determine sleep architecture, frequency and duration of apneas, and daytime sleepiness. Results indicated that participants lost $15.4 \pm 1.4 \mathrm{~kg}$ during the $\mathrm{K}$ diet and an additional $2.3 \pm 2.9 \mathrm{~kg}$ during the $\mathrm{K}+2$ diet. $\mathrm{BMI}$ decreased $5.6 \pm 0.6 \mathrm{~kg} / \mathrm{m}^{2}$ during the $\mathrm{K}$ diet and an additional $1.1 \pm 1.1 \mathrm{~kg} / \mathrm{m}^{2}$ during the $\mathrm{K}+2$ diet. Body composition studies indicated that weight was lost equally from all areas of the body and was predominantly fat and lean body mass was not significantly affected. Weight loss was accompanied by a reduction in REEnof $5.2 \pm 1.8 \mathrm{kcal} / \mathrm{kg}$ of fat-free mass per day. Blood chemistries remained normal throughout the study and included a decrease in serum cholesterol from $162 \pm 12$ to $121 \pm 8 \mathrm{mg} / \mathrm{dL}$ in the initial 4 weeks of the $\mathrm{K}$ diet. A paucity of rapid eye movement sleep and excessive slow-wave sleep were seen in all subjects at enrollment. Weight loss led to an increase in rapid eye movement sleep $(P<.02)$ and a decrease in slow-wave sleep $(P<.01)$ to near normal levels. Researchers concluded that the $\mathrm{K}$ diet could be used effectively for rapid weight loss in adolescents with morbid obesity without loss of lean body mass, with normal blood chemistries and sleep abnormalities that significantly decrease with weight loss. Although there are some clinical investigations showing promise with high protein diets, there are some concerns associated with high protein diets ${ }^{141}$.

Protein Diet Limitations. Fiber intake in high protein diets falls short in the daily-recommended allowance requirements. Dietary fiber is linked to total food intake and calorie intake. The current fiber recommendation for men is $38 \mathrm{~g}$ /day and women, 25 $\mathrm{g} / \mathrm{d}$. The recommendations differ due to unique caloric requirements for the individual genders. Americans typically consume $10-13 \mathrm{~g}$ of fiber per $1000 \mathrm{kcal}$ consumed ${ }^{142}$. The fiber level of popular protein diets ranged from $4 \mathrm{~g}$ to 10.6 of dietary fiber. Two of the most popular high protein diets, Atkins and the South Beach diet are designed with different phases of kcal/d and include dietary fiber. However, both plans do not supply recommended intakes of fiber. Despite their efforts to include fruits, vegetables, and whole grains, the dietary fiber ranges were ranging from extremely low levels of only 1.6 $\mathrm{g} / \mathrm{d}$ to less than $10 \mathrm{~g} / \mathrm{d}$ at the maximum recommendations ${ }^{142}$. Dietary fiber is an integral part of basic nutrition due to its protective effects against industrialized diseases such as diabetes, cancer, heart disease, and obesity. Researchers have also noted a link to weight management and fiber intake. In the Nurses' Health Study, weight gain was inversely associated with intake of high fiber, (i.e., whole grain foods) but positively associated with intake of refined grain foods ${ }^{142}$. There is also evidence to suggest fiber contributes to satiation. Clinical studies have found that low glycemic breakfasts, which were higher in dietary fiber, decreased food intake in preadolescent children ${ }^{143}$.

Medical specialists in the field of preventive cardiology feel that low carbohydrate, high-protein diets have shown promising results in the area of lipid profiles and weight loss. However, safety and efficacy beyond 24 weeks has yet to be determined ${ }^{144}$. Considerations for patients on low-carbohydrate-high-protein diets (LC-HP) should include the following information. The long-term (greater than 6 months) consequences of an LC-HP, hypocaloric diet are unknown, these diets do not meet the nutritional requirements for many vitamins, minerals and dietary fiber, and should not be used in a long term health plan for weight management in patients who smoke, have cardiovascular disease, diabetes, hypertension, or hyperlipidemia.. It has yet to be determined how safe LC-HP diets are in special populations ${ }^{144}$.

Low Glycemic Diets. Sugar Busters is a type of low carbohydrate, low glycemic, high protein diet ${ }^{145}$. The diet focuses on reducing high-glycemic carbohydrates to lower insulin levels and decrease insulin-resistance. The concept is to consume foods with a low-glycemic index, and fats in moderation. The Sugar Busters diet is lower in fat and protein than the Atkins, consisting of $32 \%$ of its energy from fat, $28 \%$ from protein and $40 \%$ from carbohydrate. The diet allows lean meats, eggs, non-starchy vegetables, fruits, dairy products, whole grains and nuts. It provides $280 \mathrm{mg} /$ day of cholesterol and 24 grams/day of fiber ${ }^{146}$. A study that looked at obese females in a 12-week parallel arm study followed by a 12-week crossover study found that the low-GI 
energy-restricted diet produced greater weight loss and a greater reduction in fasting insulin levels in both studies than did the isocaloric, macronutrient balanced, high-GI diet ${ }^{147}$. In another study comparing a low GI diet against a high GI diet of equal energy and macronutrient content in overweight men for 5 weeks, researchers showed that there was a reduction in total fat mass by $500 \mathrm{~g}$, as measured by dual x-ray absorptiometry ${ }^{148}$. Another study compared the effects of a reduced glycemic load diet with those of an energy-restricted, reducedfat diet in obese adolescents over a 6-month intervention and a 6-month follow-up. At 12 months, the authors found that both BMI (-1.3 $\pm .7 \mathrm{vs} .7 \pm 0.5$; $\mathrm{p}=.02)$ and fat mass $(-3.0 \pm 1.6$ vs $1.8 \pm 1.0 \mathrm{~kg} ; \mathrm{p}=$ $.01)$ were significantly lower in the reduced-GL group compared with the reduced fat group ${ }^{149}$. In a retrospective, nonrandomized study of the effects of a low-GI diet $(\mathrm{n}=64)$ compared with a conventional reduced-fat diet $(\mathrm{n}=43)$ in the management of pediatric obesity, greater decreases in BMI and body weight were seen in the low-GI group, even after adjustment for age, sex, ethnicity, baseline BMI, and baseline weight ${ }^{150}$.

Physician Supervised Diets. Many patients who are dealing with being overweight or obese accomplish weight loss with diet, exercise and lifestyle changes. Some patients may require physician supervised dietary management. The greatest loss in body weight, especially of body fat within a definite period of time is achieved by diets that provide only 400-800 kcals per day. Successful very low calorie diets (VLCDs) were associated with significantly greater maintenance of weight loss than were low calorie diets at follow up points. In a metaanalysis of 29 studies looking at long-term maintenance of weight loss in individuals completing structured weight loss programs, the initial weight loss was $17 \mathrm{~kg}$ with VLCDs vs. $6.5 \mathrm{~kg}$ with the low calorie diet. After 5 years it was $7 \mathrm{~kg}$ vs. $2 \mathrm{~kg}$ respectively ${ }^{151}$. Low fat diet plans can also be an option. Several meta-analyses show that a reduction in dietary fat without restriction of energy intake produces a modest but clinically meaningful $2.5 \mathrm{~kg}$ weight loss in overweight subjects ${ }^{152}$. Thirty-six diabetic subjects were randomly assigned to a standard behavior therapy program or to a behavior therapy program that included an 8-week period of VLCD. In this study, thirty-three of the 36 subjects completed the 20-week program and the 1-year follow-up. Use of the VLCD produced greater decreases in fasting glucose at the end of the 20 -week program and at 1-year follow-up. The VLCD group also had greater weight losses at week 20 , but weight losses from pretreatment to 1-year follow-up were similar in the two treatment groups ${ }^{153}$. In another study, researchers evaluated the use of a ketogenic, very-low-calorie diet (VLCD) in the treatment of type 2 diabetes in 20 children (mean age $14.5 \pm 0.4$ years). Mean daily blood glucose values fell from $8.9 \pm 1.1$ to $5.5 \pm 0.38 \mathrm{mmol} / \mathrm{l}(\mathrm{P}<0.0001)$ in the first 3 days of the VLCD. BMI fell from $43.5 \pm 1.8$ to $39.3 \pm 1.8 \mathrm{~kg} / \mathrm{m} 2(\mathrm{P}<0.0001)$ and HbA1c dropped from $8.8 \pm 0.6$ to $7.4 \pm 0.6 \%(\mathrm{P}<0.005)$ as the diet was continued for a mean of $60 \pm 8$ days (range 4130 days), and none required resumption of antidiabetic medications. Sustained decreases in BMI and insulin requirements were observed in patients remaining on the VLCD for at least 6 weeks when compared with those of the control group ${ }^{154}$.

\section{Physical Activity}

Modification focused on increasing physical activity should include reinforcement of physical activity and limitation of sedentary time. The theory of planned behavior has been applied extensively in the study of exercise. Behavioral intentions are determined by three independent constructs: perceived behavioral control, subjective norm (perceived social pressure to perform the behavior), and attitude (positive-negative evaluations of behavior). Thus, people are more likely to participate in physical activity if they have a positive attitude towards it, if they perceive social pressure, and if they believe they will be successful 155. Accordingly, for exercise programs to be successful for both adults and children, these dimensions need to be reinforced.

\section{Children and Adolescents}

Behavioral approaches, pharmacologic approaches, and surgical approaches are available for the treatment of overweight and obesity in children and adolescents. In addition to exercise, several dietary approaches are available. With children and adolescents, sedentary time should be limited to no more than two hours per day and physical activities should be enjoyable to reinforce participation ${ }^{127}$. Using four randomized treatment studies, Epstein et al. ${ }^{156}$, found ongoing longitudinal success after a childhood behavioral weight management intervention. After 10 years, $30 \%$ were not obese and $34 \%$ decreased percentage overweight by $20 \%$ or more. Significant effects indicate long-term changes in children depend on the treatment with emphasis on the family and other sources of support for eating and activity change. Terence ${ }^{157}$ indicates that the effect of behavioral therapy for weight loss in childhood 
may be longer lasting than that seen in adults because it may be easier to teach children healthy eating and activity habits. Also, the importance of self-control is reduced since parents regulate access to food ${ }^{157}$. In addition, cognitive-behavioral treatments seem to be more effective in children when delivered before puberty than they are for adults ${ }^{131}$.

Efforts to reduce fast-food consumption may be a useful strategy in improving diet. The National Heart, Lung, and Blood Institute Growth and Health Study is a 9-year, longitudinal biracial cohort study with annual 3-day food records. This observational study included 2379 girls (1,166 Caucasian and 1,213 African American), aged 9 or 10 years at baseline. Trends in fast-food consumption and the relationship to calorie, fat, and sodium intake were examined. Data collection occurred annually using a validated 3-day food record and a food-patterns questionnaire, which compare patterns of exposure to fast food and its impact on intake of calories, fat, and sodium. Results indicated that fast-food intake was positively associated with intake of energy and sodium as well as total fat and saturated fat as a percentage of calories. In addition, as both groups aged, fast-food intake increased in both races. The mean energy intake in the low fast-food frequency group was 1837 kcal. Sodium intake was $3085 \mathrm{mg}$, total fat was $34.3 \%$, and saturated fat was $12.5 \%$. In contrast, the adjusted mean was $1966 \mathrm{kcal}$ for the highest fastfood frequency group, sodium intake was $3236 \mathrm{mg}$, total fat was $35.8 \%$ and saturated fat was $13 \%$. Researchers concluded that dietary intake of fast food is a determinant of diet quality in both black and caucasion adolescent girls ${ }^{158}$.

Data from the same study measured the frequency of breakfast consumption, dietary calcium and fiber, and BMI by age and race. Generalized estimation equations analyses were also conducted to test whether breakfast consumption was predictive of intake of dietary calcium and fiber, as well as BMI. Results indicated that the frequency of breakfast eating declined with age and caucasion girls reported more frequent breakfast consumption than AfricanAmerican girls. However, racial difference decreased with increasing age. Higher calcium and fiber intake in all models were associated with days eating breakfast regardless of adjustment variables. In addition, days eating breakfast were predictive of lower BMI in models that adjusted for basic demographics (i.e., site, age, and race), but the independent effect of breakfast was no longer significant after parental education, energy intake, and physical activity were added to the model.
Researchers concluded that Dietetics professionals need to promote the importance of consuming breakfast to all children and adolescents, especially African-American girls ${ }^{159}$.

\section{Multifactoral Approaches}

An important development in behavioral treatment of obesity has been the attempt to identify subgroups that might benefit from specific management approaches $^{160}$. Behavioral weight management programs for participants identified with binge eating disorder is challenging due to the difficulty in collecting dietary information. Personnel who work with this population may require additional training in identifying and understanding the psychological characteristics of participants with binge-eating disorder, ${ }^{161}$ with treatment influenced by techniques developed for other types of eating disorders such as bulimia ${ }^{162}$. Also, behavioral modification is essential in managing postmenopausal obesity and overweight since regular physical activity is a crucial component of the modification for the reduction of obesity-related morbidity and mortality in the postmenopausal years ${ }^{163}$. In addition, the treatment regimen for metabolic syndrome should first include lifestyle modifications including behavioral change to reduce caloric intake and the increase of physical activity, in addition to the focus on individual components ${ }^{164}$. Behavioral strategies used in conjunction with medical treatment can be applied to adults, adolescents, and children. In a 54-week randomized, double-blind study of 539 obese adolescents, researchers concluded that when orlistat was combined with diet, exercise, and behavioral modification, there was statistically significant improvement in weight management in obese adolescents compared with placebo ${ }^{165}$.

In spite of recommendations to include behavioral modification, researchers found that lifestyle treatments, with the exception of dietary components, have not been widely used in randomized, placebocontrolled obesity-drug trials. In the 1990s, less than one-half of studies reported using behavioral strategies. A balanced-deficit diet used $41.4 \%$ of the time was the most used dietary component, lowcalorie diets were second $(24.5 \%)$, and selfmonitoring was third overall. Self-monitoring was the most used behavioral modification component and none of the other specific lifestyle treatments were implemented in more than $5 \%$ of obesity drug trials. In addition, lifestyle exercise and walking were rarely incorporated into drug studies, even in the 1990s. These data suggest that the design of 
obesity drug trials do not provide comprehensive treatments ${ }^{132}$. The first strategy in the treatment of overweight and obesity should include behavior modification. However, if not successful, other methods such as medications and surgery may be necessary.

\section{Supplements and Weight Loss}

There are several supplements available on the market to assist overweight and obese individuals with weight loss. Among the most popular and effective weight loss supplements are ephedra and caffeine. Despite a recent ban of ephedra by the Food and Drug Administration, studies have shown that together, caffeine and ephedra promote about two pounds of extra weight loss per month while dieting ${ }^{166-169}$. Greenway et al. ${ }^{168}$ found that a combination of ephedra and caffeine supplementation was a more cost-effective treatment for reducing weight, cardiac risk, and LDL cholesterol than several weight loss drugs ${ }^{170}$. Additionally, Boozer and associates ${ }^{166}$ reported that six months of herbal ephedra and caffeine supplementation promoted weight loss with no clinically significant adverse effects in healthy overweight adults ${ }^{170}$.

Among the less popular supplements that have clinically shown to have an effect on weight loss are calcium and green tea extract. Calcium has been shown to suppress fat metabolism and weight gain during periods of high calorie intake, and to increase fat metabolism during caloric restriction ${ }^{171}$. Green tea extract has been theorized to increase energy expenditure by stimulating brown adipose tissue thermogenesis ${ }^{170}$. Studies show that, with caffeine, green tea increased 24-hour energy expenditure and utilization of fat in humans ${ }^{172}$.

In addition to the previously discussed supplements, there are several other types of supplements available on the market, but there is little or no research showing the effects on weight loss. For example, Gymnema Sylvestre has been shown to affect fat metabolism, blood lipid levels, and fat deposition in rats ${ }^{173}$, but there are no published studies that have observed these same effects in humans ${ }^{170}$. Garcincia cambogia (HCA) has been shown to increase fat metabolism in animal studies ${ }^{174}$, but there is little or no evidence showing the effect of HCA supplementation on body composition in humans ${ }^{175}$. Similarly, Conjugated linoleic acids (CLA) have also been reported to decrease fat deposition in animals 176, 177 , but more recent studies indicate that CLA supplementation in humans has no effect on body composition alterations in either trained or untrained individuals ${ }^{178,}{ }^{179}$. Chromium was originally believed to improve fat loss during resistance training 180,181 , but with the use of more accurate methods of assessing body composition, studies have reported no effects on body composition in healthy individuals 182, 183. Despite the lacking evidence in support of these supplements, many are available to the public and are marketed promoting their ability to help with weight loss.

\section{Medical Management}

It may be more appropriate for some who are overweight or obese to use weight loss medications. Medications used for the treatment of obesity are formulated to reduce energy intake, increase energy output or decrease the absorption of nutrients. Diet, exercise and lifestyle changes are all still the foundation to weight loss and cannot be replaced with drugs. There are three types of medications used for the treatment of obesity and all are based on their mechanism of actions. There are medications that suppress appetite, alter nutrient absorption and increase energy expenditure ${ }^{152}$. There are two medications currently approved by the FDA for longterm use in the management of obesity; sibutramine and orlistat ${ }^{184}$.

Pharmacological. Medications should only be considered for patients with a BMI greater than 30 or greater than 27 if they have co-morbidities and have failed to lose weight on a program of diet, exercise, and behavior therapy ${ }^{185}$. Sibutramine is a novel agent that inhibits the reuptake of serotonin, norepinephrine, and dopamine ${ }^{151}$. It does not stimulate secretion of serotonin. Its affects on food intake are caused by increased noradregenic and serotonergic activity in the central nervous system ${ }^{186}$

Sibutramine has been shown to reduce energy intake, specifically during lunch time ${ }^{184}$. In a one year study, researchers examined the effect of sibutramine on weight loss. Patients in this study took a daily dose of $10 \mathrm{mg}$ of sibutramine. The results showed that the patients on sibutramine had a mean weight loss of $4.8 \mathrm{~kg}$, whereas the patients on a placebo lost a mean of $1.8 \mathrm{~kg}$. Orlistat is an agent that inhibits gastrointestinal lipase. The resulting lower gut enzyme activity reduces by approximately one third the amount of fat that is absorbed from food. It is a reversible inhibitor and it binds covalently in the lumen with the active serine residue of gastric and pancreatic lipases. Depending on the fat content of a person's diet, this lowered absorption can represent 150 to $200 \mathrm{kcal} /$ day ${ }^{187}$. Orlistat does 
not affect the central nervous system and does not have a direct affect on appetite. It induces weight loss by principally blocking the absorption of about one third of the fat consumed in a meal ${ }^{184}$. A study that was consistent with the idea reported that fat intake was generally higher in placebo group than in the orlistat treated group ${ }^{184}$. A clinical investigation required participants to follow a low fat energy restricted diet and take $120 \mathrm{mg}$ of orlistat 3 times a day or a placebo for one year. The mean weight loss was $9 \%$ in the orlistat group vs. a mean weight loss of $5.8 \%$ in the placebo group ${ }^{185}$.

Medical Management with Behavior Change. Medication is often recommended to individuals who have difficulty losing weight with diet, exercise, and behavior therapy. There is growing evidence that shows that a program consisting of physical activity can reduce the risk for cardiovascular disease. By introducing a behavior treatment that encourages a person to eat low fat, low-cholesterol foods, they reduce the risk of coronary artery disease. In addition, if a lifestyle modification was not employed in combination with obesity medications, medications alone might result in suboptimal short and long-term weight losses. Adding pharmacotherapy to lifestyle modification fits well with a stepped care approach in which the least aggressive intervention is tried first and then, if unsuccessful, is augmented by more aggressive interventions ${ }^{184}$.

There have been multiple studies done to examine whether adding medications will improve the results of lifestyle modification. In a study done with sibutramine, results showed a weight loss of 3 to 9 $\mathrm{kg}$ greater than placebo when both interventions were combined with a low intensity program of lifestyle modification ${ }^{184}$. In a study using orlistat plus lifestyle modification, weight losses were 2 to $6 \mathrm{~kg}$ greater than those resulting from placebo plus lifestyle change ${ }^{184}$. In a studies of 1 to 2 years in durations, sibutramine produced an average weight loss of 7 to $10 \mathrm{~kg}$, which was $5 \mathrm{~kg}$ greater than placebo plus lifestyle change. In a two year study orlistat produced weight loss averaging 5 to $8 \mathrm{~kg}$, which was $4 \mathrm{~kg}$ greater than the placebo.

Other Medical Options. Bariatric surgery can be an option for some obese individuals if the patient has a BMI $\geq 40 \mathrm{~kg} / \mathrm{m}^{2}$, BMI of 35 to $40 \mathrm{~kg} / \mathrm{m}^{2}$ who have a high risk of co-morbid conditions or have significantly obese related physical conditions that interfere with their lifestyle. There are two procedures commonly performed. One is vertical banded gastroplasty, in which a small pouch with a restricted outlet is constructed along the lesser curvature of the stomach. The second is gastric bypass, in which a proximal gastric pouch is constructed whose outlet is a Y-shaped limb of the small intestine ${ }^{152}$. Life long medical surveillance is necessary after surgical therapy ${ }^{151}$. Health Insurance Commission data indicate a steady and steep increase in bariatric surgery with 399 procedures, mainly gastric stapling of various types, performed in 1993 and 2,992 procedures in $2003{ }^{188}$. Depending on the procedure and the program, the surgery and related care may cost $\$ 20,000$ to $\$ 50,000$ 189 . The major complications of bariatric surgery include pulmonary embolism, respiratory failure, gastrointestinal leaks from the breakdown of the staple or suture line, stomal obstruction or stenosis, and bleeding ${ }^{189}$. The risk of death following bariatric surgery is between $1 \%$ and $2 \%$ in most series, but is significantly higher in patients with respiratory insufficiency of obesity ${ }^{190}$.

\section{RESEARCH DESIGN CONSIDERATIONS IN THE STUDY OF OBESITY}

A good research design begins with a valid question that needs to be answered. Over the last 25 years, there has been a growing need for sound research in the area of obesity and weight management. With the incidence of "over weight" in the United States increasing to over $64 \%$, the need for treatment has risen. The research design begins with assessing the feasibility of the study objectives and considering alternative research designs. The researcher must then define the study population and key concepts in operational terms. Special care must be given in selecting methods of sampling, data collection, and analysis appropriate to the study's objectives. Finally, the research team must develop realistic budgets and time schedules for each stage of the research.

\section{Research Question and Experimental Design}

The research design must begin with a valid question. The question must have a need to be answered within the scientific community. The research facility must have the ability, such as personnel and equipment, to answer the question. Furthermore, the research design must be one that controls for the largest amount of error and bias, at the same time clearly addressing the research question. A meta-analysis ${ }^{191}$ completed in 1997 concluded that in over 700 research studies reviewed diet plus exercise was the most effective treatment in weight reduction. Classic 
experimental methods employed to test specificallydesigned hypothesis about diet-disease relationship should be a randomized control trial ${ }^{109}$. A randomized controlled trial (RCT) is an experiment in which investigators randomly assign eligible subjects into groups to receive or not receive one or more interventions that are being compared. The results are analyzed by comparing outcomes in the groups. RCT studies help control confounding variables associated with this type of research. Control subjects are included in clinical trials to quantify and correct for the influence of compounding or confounding factors that introduce bias to the results of a specific treatment. Therefore all studies assessing the effectiveness of a treatment in achieving weight loss must include a control or comparison group, irrespective of whether they are examining drugs, diet, lifestyle or other treatments 109. Subjects in an RCT could not be randomly assigned to lose or not lose weight; they could only be randomly assigned to receive or not receive interventions that might result in weight loss ${ }^{160}$. If participants in an RCT were randomly assigned to several interventions that produce weight loss through different mechanisms and these interventions yielded similar improvements in health status, then the conclusion that weight loss was responsible for the improvements in health outcomes may be justified ${ }^{160}$.

\section{Study Subjects}

Carefully selecting a study design and population facilitates the creation of new knowledge while avoiding important errors. The overwhelming majority of subjects that have been used in weight loss trials have been moderately obese and middle aged ${ }^{191}$. Furthermore, the subjects' demographics have had little variation. On average subjects' demographics were age (40y), body weight $(96 \mathrm{~kg})$, BMI (35), and program length $(15 \mathrm{w}){ }^{191}$. A significant source of error is that subjects who volunteer for studies of weight loss want to lose weight so they are ready to attempt to make lifestyle changes. Their recruitment with overweight as a selection criterion usually results in weight loss in addition to or even without specific treatment or advice. Control groups for diet and lifestyle studies may be offered no advice, or usual or routine treatment, but this may confuse the analysis because such subjects recruited as volunteers for weight loss inevitably do make extra changes, thus lose weight to a variable degree.

\section{Sources of Error and Bias}

Many sources of error and bias exist when conducting obesity and weight management research. The goal of the research team is to identify and attempt to control for those variables. Various physical, psychological, and emotional factors may complicate obesity treatment and/or interpretation of results. As previously mentioned the participants themselves are the cause of some error. Subjects recruited based on weight, BMI, and sedentary lifestyles are looking to make a lifestyle change. Thus, it must be expected that even the controls might loose weight. According to Yanovski ${ }^{160}$, it may be feasible to maintain control groups who do not lose weight in long-term studies by providing them with a minimal intervention of a self-help manual on weight loss and healthy eating. Obese control groups often have greater retention rates than do treatment groups. This result is believed to be attributable to the control group members feeling less embarrassed than their intervention group counterparts if they do not lose weight or if they regain lost weight ${ }^{160}$.

One of the primary issues in obesity research is that of diet records. Over the last several years, the importance of evaluation of nutritional intervention with exercise has come to be a top priority. However, one of the largest sources of error is that of dietary recall. In a perfect world, researchers could monitor all food intake for there study participants. This is logistically impossible, unless your participants are in house. Thus, all conventional methods of dietary adherence depend on subjects' reports. Most labs lack independent biochemical, physiological or genetic measures of dietary intake. Therefore, we do not know if subjects actually follow the diets being tested and compared. We also know that most subjects in "weight loss" studies underreport their energy intake and its components ${ }^{192}$. The sad reality is that we do not actually know if the results of any current diet trials are valid or reliable. Winkler ${ }^{193}$ has identified three ways in which researchers can help control diet intervention studies: (1) biomarkers of intake for energy, macro- and micro-nutrients and other food components relevant to weight gain/loss; (2) field measuring instruments that are cheap, rapid, painless, non-intrusive and selfadministrable; and (3) electronic data transmission systems that preclude subjects' ability to misreport.

Other sources of error include few entry criteria for participants, pre-menstrual fluid accumulation (gender), recruiting participants who have already 
participated in weight-loss studies, insufficient statistical power, too short study duration, poor matching for age, or unusual age distribution, just to name a few ${ }^{109}$. No study will be able to control for all of these sources of error, thus care should be taken to limit the impact of these sources of error/bias and/or account for them in statistical analysis. One of the areas that the researchers can control is that of collection and recording of data. Researchers should use the most valid and reliable forms of measurement available to them such as DEXA for body composition and bone density ${ }^{194}$, Calibrated digital scale, and BIA for body water ${ }^{195}$. Researchers can also limit error by providing metabolic data, such as that of REEor VO2 measurements while exercising.

\section{Future Directions}

In 2004, the Department of Health and Human Services (DHHS) in collaboration with National Institutes of Health (NIH) created a program announcement to outline the type of obesity/weight loss research that is needed ${ }^{196}$. As previously mentioned and outlined through meta-analysis ${ }^{191}$, weight loss research has been narrowly focused on the population and time frame. With this mind, the DHHS and NIH have outlined ten areas that should be the focus of future research as follows:

1) Studies that investigate biological mechanisms underlying weight regain after intentional weight loss (neuroendocrine, endocrine, and gastrointestinal function, muscle and adipocyte biology, etc);

2) Investigations of appetite and food intake during weight maintenance and regain periods (including energy intake, macronutrient preference, micronutrient intake from foods and supplements, eating behaviors, binge-eating);

3) Studies to elucidate the role of energy expenditure during weight regain after intentional weight loss (including voluntary physical activity, thermic effect of feeding, nonexercise-activity thermogenesis, sympathetic/parasympathetic nervous system function);

4) Studies of the effects of age-related changes on responses to weight maintenance interventions, including effects on body composition, metabolic regulation and other physiologic responses;
5) Clinical studies that evaluate the impact of behavioral interventions such as extended or more frequent patient contact, use of technology to enhance self-monitoring behaviors, social supports, motivational interviewing, etc. on improved weight maintenance;

6) Studies of dietary strategies to enhance long-term weight maintenance (such as meal replacements, alterations in nutrient density or macronutrient composition);

7) Studies using approved or investigational weight loss agents to enhance weight maintenance or prevent regain after weight loss;

8) Clinical studies evaluating the impact of differing types, intensity, and frequency of physical activity on long-term weight maintenance;

9) Innovative interventions that incorporate the sociodemographic and cultural factors thought to influence weight maintenance;

10) Innovative methods to promote longterm weight maintenance in persons with mobility-limiting conditions.

\section{Athletes and Weight Loss}

As stated above, weight loss is achieved by a decrease in energy intake and an increase in energy expenditure. In the case of an athlete, it is assumed that energy expenditure is adequate. Therefore, the focus of an athlete wanting to lose fat mass should be on energy intake. Prior to reducing caloric intake, it is imperative that a preliminary body composition assessment be completed ${ }^{197}$. This is necessary so that changes in fat mass and fat free mass can be documented throughout the reduction in energy intake. It is important (especially for the athlete) that the bodyweight lost is a result of a reduction of fat mass and not skeletal muscle. After an initial body composition assessment, periodic assessments should follow. When efforts to induce these body changes are approached with sound principles of nutrition and training, the resulting changes in body composition can make the desired contribution to health and fitness as well as contributing to increasing the athlete's performance potential ${ }^{198}$.

Body weight goals of athletes should be individualized and based on the requirements of the sport, the athlete's body size and shape, and in consultation with the athlete, coaches, and trainers. Safe weight loss goals should be established on an 
individual basis ${ }^{199}$. Athletes, coaches, and trainers should work closely with individuals who have training in nutrition (registered dietitians and sports nutritionists) to set appropriate weight goals and to develop weight management protocols that promote healthy eating ${ }^{199}$. Athletes who use drastic food or fluid restriction to lose weight may experience negative consequences, including loss of lean tissue, hormonal disturbances, and performance impairment 200 . While there are no standard guidelines set for athletes in terms of the amounts of caloric restriction, some recommendations have been given: decreasing energy intake by $500 \mathrm{kcal} /$ day or 300 to $520 \mathrm{kcal} /$ day ${ }^{201}$; consuming $38 \mathrm{kal} / \mathrm{kg}(17 \mathrm{kcal} / \mathrm{lb})$ for men and 35 $\mathrm{cal} / \mathrm{kg}(16 \mathrm{kcal} / \mathrm{lb})$ for women ${ }^{202}$.

In summary, weight loss is not commonly the goal of athletes. However, when weight loss is desired, it is important that the resultant decreases in body weight be directed towards fat mass. Following the aforementioned strategies may assist the athlete in accomplishing their weight loss goals.

\section{CONCLUSION}

The prevalence of morbidly obese Americans is estimated to have increased three-fold from 1990 to 2000. Obesity is not only a problem in the United States but is also a major health concern in Europe and other regions of the world. The associated effect of obesity on type 2 diabetes, hypertension, coronary heart disease (CHD), gallbladder disease, osteoarthritis, and certain cancers gives rise to the increasing economic costs of obesity. The total annual medical expenditure cost for the United States has been estimated to be $5-7 \%$ of total health care costs or about 75 billion dollars a year. Thus, the need for preventative techniques, as well as, treatment has never been greater. Historically, obesity has been thought to simply be related to an imbalance between energy intake and expenditure. However, more recent research has suggested that genetic, physiological, and behavioral factors also play a significant role in the etiology of obesity. There are many ways to treat and prevent obesity. Today's market is flooded with weight loss drugs, surgeries, and fad diets. However, eating a proper diet and maintaining a relatively active lifestyle is the most effective means to prevent and treat obesity. Although it seems simple enough, there is still a need for research in this area. There needs to be further research on the genetic and hormonal aspects of obesity such as CCK, grehlin, leptin, and cortisol. There is also a strong need for long-term weight maintenance studies. Commonly research focuses on short-term weight loss, but not maintaining the weight loss. Finally, there is a need to study the effects of obesity in sports. In recent weeks, some questions have been raised about the health of professional athletes who carry $300+$ pounds. While most are athletically talented, they are still clinically obese. Thus, there is a growing need to evaluate the physical stress associated with obesity in athletes.

\section{REFERENCES}

1. Bray, GaB, C, Handbook of Obesity: Etiology and Pathophysiology. 2 ed. 2004: Marcel Dekker Inc. 1200.

2. Deurenberg, $\mathrm{P}$ and Yap M: The assessment of obesity: methods for measuring body fat and global prevalence of obesity. Baillieres Best Pract Res Clin Endocrinol Metab, 1999. 13(1): p. 1-11.

3. Weisell, RC: Body mass index as an indicator of obesity. Asia Pac J Clin Nutr, 2002. 11 Suppl 8: p. S681-4.

4. Gregg, EW, Cheng YJ, Cadwell BL, et al.: Secular trends in cardiovascular disease risk factors according to body mass index in US adults. JAMA, 2005. 293(15): p. 1868-74.

5. Freedman, DS, Khan LK, Serdula MK, et al.: Trends and correlates of class 3 obesity in the United States from 1990 through 2000. JAMA, 2002. 288(14): p. 1758-61.

6. Ogden, CL, Flegal KM, Carroll MD, et al.: Prevalence and trends in overweight among US children and adolescents, 1999-2000. JAMA. 2002 Oct 9;288(14):1728-32., 2002. 288(14): p. 1728-32.

7. Seidell, JC and Flegal KM: Assessing obesity: classification and epidemiology. Br Med Bull, 1997. 53(2): p. $238-52$.

8. Cockram, CS: The epidemiology of diabetes mellitus in the Asia-Pacific region. Hong Kong Med J, 2000. 6(1): p. 43-52.

9. Gill, TP: Cardiovascular risk in the Asia-Pacific region from a nutrition and metabolic point of view: abdominal obesity. Asia Pac J Clin Nutr, 2001. 10(2): p. 85-9.

10. Heshka S, AJ, Atkinson RL, Greenway FL, Hill JO, Phinney SD, Kolotkin RL, Miller-Kovach K, Pi-Sunyer FX: Weight loss with self-help compared with a structured commercial program: a randomized trial. JAMA, 2003. 289: p. 1792-1798.

11. Colditz, GA: Economic costs of obesity and inactivity. Med Sci Sports Exerc, 1999. 31(11 Suppl): p. S663-7.

12. Finkelstein, EA, Ruhm CJ, and Kosa KM: Economic causes and consequences of obesity. Annu Rev Public Health, 2005. 26: p. 239-57.

13. Quesenberry, CP, Jr., Caan B, and Jacobson A: Obesity, health services use, and health care costs among members of a health maintenance organization. Arch Intern Med, 1998. 158(5): p. 466-72.

14. Thompson, D, Brown JB, Nichols GA, et al.: Body mass index and future healthcare costs: a retrospective cohort study. Obes Res, 2001. 9(3): p. 210-8. 
15. Finkelstein, EA, Fiebelkorn IC, and Wang G: National medical spending attributable to overweight and obesity: how much, and who's paying? Health Aff (Millwood), 2003. Suppl Web Exclusives: p. W3-219-26.

16. Birmingham, CL, Muller JL, Palepu A, et al.: The cost of obesity in Canada. Cmaj, 1999. 160(4): p. 483-8.

17. Murphy, C and Yates J: Economic comparison of weight loss programmes versus drug treatment for the management of obesity. Asia Pac J Clin Nutr, 2005. 14(Suppl): p. S97-S105.

18. Manson, JE, Stampfer MJ, Hennekens CH, et al.: Body weight and longevity:a reassessment. JAMA, 1987. 257: p. $353-358$.

19. Andres, R, Muller DC, and Sorkin JD: Long-term effects of change in body weight on all-cause mortality. A review. Annals of Internal Medicine, 1993. 110: p. 737-743.

20. Stevens, J: Impact of age on associations between weight and mortality. Nutr Rev, 2000. 58: p. 129-137.

21. Stevens, J, Cai J, Pamuk ER, et al.: The effects of age on the association between body mass index and mortality. New England Journal of Medicine, 1998. 338: p. 1-7.

22. Jequier, E and Tappy L: Regulation of body weight in humans. Physiol Rev, 1999. 79(2): p. 451-80.

23. Spiegelman, BM and Flier JS: Obesity and the regulation of energy balance. Cell, 2001. 104(4): p. 531-43.

24. Flatt, JP, Ravussin E, Acheson KJ, et al.: Effects of dietary fat on postprandial substrate oxidation and on carbohydrate and fat balances. J Clin Invest, 1985. 76(3): p. 1019-24.

25. Schutz, Y, Flatt JP, and Jequier E: Failure of dietary fat intake to promote fat oxidation: a factor favoring the development of obesity. Am J Clin Nutr, 1989. 50(2): p. 307-14.

26. Jequier, E: Nutrient effects: post-absorptive interactions. Proc Nutr Soc, 1995. 54(1): p. 253-65.

27. Labayen, I, Diez N, Gonzalez A, et al.: Effects of protein vs. carbohydrate-rich diets on fuel utilisation in obese women during weight loss. Forum Nutr, 2003. 56: p. 168-70.

28. Skov, AR, Toubro S, Ronn B, et al.: Randomized trial on protein vs carbohydrate in ad libitum fat reduced diet for the treatment of obesity. Int J Obes Relat Metab Disord, 1999. 23(5): p. 528-36.

29. Baba, NH, Sawaya S, Torbay N, et al.: High protein vs high carbohydrate hypoenergetic diet for the treatment of obese hyperinsulinemic subjects. Int J Obes Relat Metab Disord, 1999. 23(11): p. 1202-6.

30. Farnsworth, E, Luscombe ND, Noakes M, et al.: Effect of a high-protein, energy-restricted diet on body composition, glycemic control, and lipid concentrations in overweight and obese hyperinsulinemic men and women. Am J Clin Nutr, 2003. 78(1): p. 319.

31. Noakes, M, Keogh JB, Foster PR, et al.: Effect of an energy-restricted, high-protein, low-fat diet relative to a conventional highcarbohydrate, low-fat diet on weight loss, body composition, nutritional status, and markers of cardiovascular health in obese women. Am J Clin Nutr, 2005. 81(6): p. 1298-306.

32. Brinkworth, GD, Noakes M, Keogh JB, et al.: Long-term effects of a high-protein, low-carbohydrate diet on weight control and cardiovascular risk markers in obese hyperinsulinemic subjects. Int J Obes Relat Metab Disord, 2004. 28(5): p. 661-70.

33. Luscombe, ND, Clifton PM, Noakes M, et al.: Effect of a high-protein, energy-restricted diet on weight loss and energy expenditure after weight stabilization in hyperinsulinemic subjects. Int J Obes Relat Metab Disord, 2003. 27(5): p. 582-90.

34. St-Onge, MP, Ross R, Parsons WD, et al.: Medium-chain triglycerides increase energy expenditure and decrease adiposity in overweight men. Obes Res, 2003. 11(3): p. 395-402.

35. Ello-Martin, JA, Ledikwe JH, and Rolls BJ: The influence of food portion size and energy density on energy intake: implications for weight management. Am J Clin Nutr, 2005. 82(1 Suppl): p. 236S-241S.

36. Rolls, BJ, Ello-Martin JA, and Tohill BC: What can intervention studies tell us about the relationship between fruit and vegetable consumption and weight management? Nutr Rev, 2004. 62(1): p. 1-17.

37. Tohill, BC, Seymour J, Serdula M, et al.: What epidemiologic studies tell us about the relationship between fruit and vegetable consumption and body weight. Nutr Rev, 2004. 62(10): p. 365-74.

38. Epstein, LH, Gordy CC, Raynor HA, et al.: Increasing fruit and vegetable intake and decreasing fat and sugar intake in families at risk for childhood obesity. Obes Res, 2001. 9(3): p. 171-8.

39. Viguerie, N, Vidal H, Arner P, et al.: Adipose tissue gene expression in obese subjects during low-fat and high-fat hypocaloric diets. Diabetologia, 2005. 48(1): p. 123-31.

40. Bastard, JP, Hainque B, Dusserre E, et al.: Peroxisome proliferator activated receptor-gamma, leptin and tumor necrosis factoralpha mRNA expression during very low calorie diet in subcutaneous adipose tissue in obese women. Diabetes Metab Res Rev, 1999. 15(2): p. 92-8.

41. Faith, MS, Rha SS, Neale MC, et al.: Evidence for genetic influences on human energy intake: results from a twin study using measured observations. Behav Genet, 1999. 29(3): p. 145-54.

42. Levine, JA and Kotz CM: NEAT - non-exercise activity thermogenesis - egocentric \& geocentric environmental factors vs. biological regulation. Acta Physiol Scand, 2005. 184(4): p. 309-18.

43. Hill, O, Saris W, and Levine J, The Handbook of Obesity: Etiology and Pathophysiology. Second ed, ed. G.A.B.a.C. Bouchard. 2004, New York: Marcel Dekker Inc.

44. Dauncey, MJ: Activity and energy expenditure. Can J Physiol Pharmacol, 1990. 68(1): p. 17-27.

45. Castaneda, TR, Jurgens H, Wiedmer P, et al.: Obesity and the neuroendocrine control of energy homeostasis: the role of spontaneous locomotor activity. J Nutr, 2005. 135(5): p. 1314-9.

46. DiPietro, L: Physical activity, body weight, and adiposity: an epidemiologic perspective. Exerc Sport Sci Rev, 1995. 23: p. 275303.

47. Meredith, CN, Zackin MJ, Frontera WR, et al.: Body composition and aerobic capacity in young and middle-aged endurancetrained men. Med Sci Sports Exerc, 1987. 19(6): p. 557-63.

48. Ballor, DL and Keesey RE: A meta-analysis of the factors affecting exercise-induced changes in body mass, fat mass and fat-free mass in males and females. Int J Obes, 1991. 15(11): p. 717-26.

49. Slentz, CA, Aiken LB, Houmard JA, et al.: Inactivity, exercise and visceral fat. STRRIDE: a randomized, controlled study of exercise intensity and amount. J Appl Physiol, 2005. 
50. Williams, PT, Blanche PJ, and Krauss RM: Behavioral versus genetic correlates of lipoproteins and adiposity in identical twins discordant for exercise. Circulation, 2005. 112(3): p. 350-6.

51. Giorgino, F, Laviola L, and Eriksson JW: Regional differences of insulin action in adipose tissue: insights from in vivo and in vitro studies. Acta Physiol Scand, 2005. 183(1): p. 13-30.

52. Rorive, M, Letiexhe MR, Scheen AJ, et al.: [Obesity and type 2 diabetes]. Rev Med Liege, 2005. 60(5-6): p. 374-82.

53. Pinkney, J and Kopelman P, eds. Handbook of Obesity: Etiology and Pathophysiology. Second ed., ed. G.A.B.a.C. Bouchard. 2004, Marcel Dekker, Inc: New York. 1046.

54. Lafontan, M: Fat cells: afferent and efferent messages define new approaches to treat obesity. Annu Rev Pharmacol Toxicol, 2005. 45: p. 119-46.

55. Cases, JA, Gabriely I, Ma XH, et al.: Physiological increase in plasma leptin markedly inhibits insulin secretion in vivo. Diabetes, 2001. 50(2): p. 348-52.

56. Schwartz, MW, Woods SC, Porte D, Jr., et al.: Central nervous system control of food intake. Nature, 2000. 404(6778): p. 66171.

57. Banks, AS, Davis SM, Bates SH, et al.: Activation of downstream signals by the long form of the leptin receptor. J Biol Chem, 2000. 275(19): p. 14563-72.

58. Considine, RV, Considine EL, Williams CJ, et al.: The hypothalamic leptin receptor in humans: identification of incidental sequence polymorphisms and absence of the $\mathrm{db} / \mathrm{db}$ mouse and fa/fa rat mutations. Diabetes, 1996. 45(7): p. 992-4.

59. Considine, RV, Sinha MK, Heiman ML, et al.: Serum immunoreactive-leptin concentrations in normal-weight and obese humans. N Engl J Med, 1996. 334(5): p. 292-5.

60. Sahu, A and Kalra S: Neuropeptidergic regulation of feeding behavior: Neuropeptide Y. Trends Endocrinol Metab, 1993. 4: p. 217-224.

61. Baranowska, B, Wolinska-Witort E, Wasilewska-Dziubinska E, et al.: The role of neuropeptides in the disturbed control of appetite and hormone secretion in eating disorders. Neuro Endocrinol Lett, 2003. 24(6): p. 431-4.

62. Epel, E, Lapidus R, McEwen B, et al.: Stress may add bite to appetite in women: a laboratory study of stress-induced cortisol and eating behavior. Psychoneuroendocrinology, 2001. 26(1): p. 37-49.

63. Bjorntorp, P and Rosmond R: Obesity and cortisol. Nutrition, 2000. 16(10): p. 924-36.

64. Drapeau, V, Therrien F, Richard D, et al.: Is visceral obesity a physiological adaptation to stress? Panminerva Med, 2003. 45(3): p. 189-95.

65. Dallman, MF, la Fleur SE, Pecoraro NC, et al.: Minireview: glucocorticoids--food intake, abdominal obesity, and wealthy nations in 2004. Endocrinology, 2004. 145(6): p. 2633-8.

66. Cummings, DE, Purnell JQ, Frayo RS, et al.: A preprandial rise in plasma ghrelin levels suggests a role in meal initiation in humans. Diabetes, 2001. 50(8): p. 1714-9.

67. Shintani, M, Ogawa Y, Ebihara K, et al.: Ghrelin, an endogenous growth hormone secretagogue, is a novel orexigenic peptide that antagonizes leptin action through the activation of hypothalamic neuropeptide Y/Y1 receptor pathway. Diabetes, 2001. 50(2): p. 227-32.

68. Bray, GA, Contemporary Diagnosis and Management of Obesity and The Metabolic Syndrome. Third Edition ed. 2003, Newtown, Pennsylvania: Handbooks in Health Care, Co. 328.

69. Vgontzas, AN, Papanicolaou DA, Bixler EO, et al.: Elevation of plasma cytokines in disorders of excessive daytime sleepiness: role of sleep disturbance and obesity. J Clin Endocrinol Metab, 1997. 82(5): p. 1313-6.

70. Trujillo, ME, Sullivan S, Harten I, et al.: Interleukin-6 regulates human adipose tissue lipid metabolism and leptin production in vitro. J Clin Endocrinol Metab, 2004. 89(11): p. 5577-82.

71. Pasquali, R, Vicennati V, and Pagotto U, eds. Handbook of Obesity: Etiology and Pathophysiology. second ed., ed. G.A.B.a.C. Bouchard. 2004, Marcel Dekker: New York. 1046.

72. Aycan, Z, Berberoglu M, Ocal G, et al.: Relationship between plasma leptin, insulin and tumor necrosis factor alpha in obese children. J Pediatr Endocrinol Metab, 2005. 18(3): p. 275-84.

73. Schoemaker, RC, Buijs MM, Pijl H, et al.: Modeling the influence of growth hormone on lipolysis. J Pharmacokinet Pharmacodyn, 2002. 29(2): p. 157-70.

74. Hansen, TK: Pharmacokinetics and acute lipolytic actions of growth hormone. Impact of age, body composition, binding proteins, and other hormones. Growth Horm IGF Res, 2002. 12(5): p. 342-58.

75. Iacobellis, G, Ribaudo MC, Zappaterreno A, et al.: Relationship of thyroid function with body mass index, leptin, insulin sensitivity and adiponectin in euthyroid obese women. Clin Endocrinol (Oxf), 2005. 62(4): p. 487-91.

76. Koppeschaar, HP, Meinders AE, and Schwarz F: Metabolic responses in grossly obese subjects treated with a very-low-calorie diet with and without triiodothyronine treatment. Int J Obes, 1983. 7(2): p. 133-41.

77. Bray, G: Commentary on Banting letters. Obes Res, 1993. 1: p. 148-152.

78. Huszar, D, Lynch CA, Fairchild-Huntress V, et al.: Targeted disruption of the melanocortin-4 receptor results in obesity in mice. Cell, 1997. 88(1): p. 131-41.

79. Bray, GA and Greenway FL: Current and potential drugs for treatment of obesity. Endocr Rev, 1999. 20(6): p. 805-75.

80. Brennan, IM, Feltrin KL, Horowitz M, et al.: Evaluation of interactions between CCK and GLP-1 in their effects on appetite, energy intake, and antropyloroduodenal motility in healthy men. Am J Physiol Regul Integr Comp Physiol, 2005. 288(6): p. R1477-85.

81. Bjorntorp, P: Body fat distribution, insulin resistance, and metabolic diseases. Nutrition, 1997. 13(9): p. 795-803.

82. Oren, S, Grossman E, and Frohlich ED: Arterial and venous compliance in obese and nonobese subjects. Am J Cardiol, 1996. 77(8): p. 665-7.

83. Rauch, U, Osende JI, Fuster V, et al.: Thrombus formation on atherosclerotic plaques: pathogenesis and clinical consequences. Ann Intern Med, 2001. 134(3): p. 224-38.

84. Booth, FW. Pieces of the Same Human Puzzle: Evolution, Physical Activity, Chronic Disease, Public Health and Policy. in American College of Sports Medicine. 2005. Nashville, TN. 
85. Pearson, TA and Derby CA: Invited commentary: should arteriographic case-control studies be used to identify causes of atherosclerotic coronary artery disease? Am J Epidemiol, 1991. 134(2): p. 123-8.

86. Clark, LT, Karve MM, Rones KT, et al.: Obesity, distribution of body fat and coronary artery disease in black women. Am J Cardiol, 1994. 73(12): p. 895-6.

87. Rexrode, KM, Carey VJ, Hennekens CH, et al.: Abdominal adiposity and coronary heart disease in women. Jama, 1998. 280(21): p. 1843-8.

88. Hubert, HB, Feinleib M, McNamara PM, et al.: Obesity as an independent risk factor for cardiovascular disease: a 26-year follow-up of participants in the Framingham Heart Study. Circulation, 1983. 67(5): p. 968-77.

89. Stamler, R, Stamler J, Riedlinger WF, et al.: Weight and blood pressure. Findings in hypertension screening of 1 million Americans. Jama, 1978. 240(15): p. 1607-10.

90. Landsberg, L: Obesity and hypertension: experimental data. J Hypertens Suppl, 1992. 10(7): p. S195-201.

91. Meehan, WP, Darwin CH, Maalouf NB, et al.: Insulin and hypertension: are they related? Steroids, 1993. 58(12): p. 621-34.

92. Rocchini, AP, Moorehead C, DeRemer S, et al.: Hyperinsulinemia and the aldosterone and pressor responses to angiotensin II. Hypertension, 1990. 15(6 Pt 2): p. 861-6.

93. Krief, S, Lonnqvist F, Raimbault S, et al.: Tissue distribution of beta 3-adrenergic receptor mRNA in man. J Clin Invest, 1993. 91(1): p. 344-9.

94. Anderson, EA, Hoffman RP, Balon TW, et al.: Hyperinsulinemia produces both sympathetic neural activation and vasodilation in normal humans. J Clin Invest, 1991. 87(6): p. 2246-52.

95. Wu, HY, Jeng YY, Yue CJ, et al.: Endothelial-dependent vascular effects of insulin and insulin-like growth factor I in the perfused rat mesenteric artery and aortic ring. Diabetes, 1994. 43(8): p. 1027-32.

96. Collins, S, Kuhn CM, Petro AE, et al.: Role of leptin in fat regulation. Nature, 1996. 380(6576): p. 677.

97. Golden, PL, Maccagnan TJ, and Pardridge WM: Human blood-brain barrier leptin receptor. Binding and endocytosis in isolated human brain microvessels. J Clin Invest, 1997. 99(1): p. 14-8.

98. Letiexhe, MR, Scheen AJ, Gerard PL, et al.: Insulin secretion, clearance and action before and after gastroplasty in severely obese subjects. Int J Obes Relat Metab Disord, 1994. 18(5): p. 295-300.

99. Mavri, A, Stegnar M, Sentocnik JT, et al.: Impact of weight reduction on early carotid atherosclerosis in obese premenopausal women. Obes Res, 2001. 9(9): p. 511-6.

100. Giltay, EJ, Lambert J, Elbers JM, et al.: Arterial compliance and distensibility are modulated by body composition in both men and women but by insulin sensitivity only in women. Diabetologia, 1999. 42(2): p. 214-21.

101. Chi, MM, Hintz CS, Henriksson J, et al.: Chronic stimulation of mammalian muscle: enzyme changes in individual fibers. Am J Physiol, 1986. 251(4 Pt 1): p. C633-42.

102. Messerli, FH, Nunez BD, Ventura HO, et al.: Overweight and sudden death. Increased ventricular ectopy in cardiopathy of obesity. Arch Intern Med, 1987. 147(10): p. 1725-8.

103. Zemva, A and Zemva Z: Ventricular ectopic activity, left ventricular mass, hyperinsulinemia, and intracellular magnesium in normotensive patients with obesity. Angiology, 2000. 51(2): p. 101-6.

104. Lapidus, L, Bengtsson C, Larsson B, et al.: Distribution of adipose tissue and risk of cardiovascular disease and death: a 12 year follow up of participants in the population study of women in Gothenburg, Sweden. Br Med J (Clin Res Ed), 1984. 289(6454): p. 1257-61.

105. Ness, J, Aronow WS, and Ahn C: Risk factors for symptomatic peripheral arterial disease in older persons in an academic hospital-based geriatrics practice. J Am Geriatr Soc, 2000. 48(3): p. 312-4.

106. Plavnik, FL, Ajzen S, Kohlmann O, Jr., et al.: Intima-media thickness evaluation by B-mode ultrasound. Correlation with blood pressure levels and cardiac structures. Braz J Med Biol Res, 2000. 33(1): p. 55-64.

107. Kannel, WB, Plehn JF, and Cupples LA: Cardiac failure and sudden death in the Framingham Study. Am Heart J, 1988. 115(4): p. 869-75.

108. Association, AH: Heart Disease and Stroke Statistics - 2005 Update. 2005, American Heart Association: Dallas.

109. Finer, N, Bloom SR, Frost GS, et al.: Sibutramine is effective for weight loss and diabetic control in obesity with type 2 diabetes: a randomised, double-blind, placebo-controlled study. Diabetes Obes Metab, 2000. 2(2): p. 105-12.

110. Hauner, H: The impact of pharmacotherapy on weight management in type 2 diabetes. Int J Obes Relat Metab Disord, 1999. 23 Suppl 7: p. S12-7.

111. Williams, KV, Mullen ML, Kelley DE, et al.: The effect of short periods of caloric restriction on weight loss and glycemic control in type 2 diabetes. Diabetes Care, 1998. 21(1): p. 2-8.

112. Duggirala, R, Mitchell BD, Blangero J, et al.: Genetics determinants of variation in gallbladder disease in the Mexican-American population. Genetic Epidemiology, 1999. 16(2): p. 191-204.

113. Acalovschi, M and Blendea D: Risk of asymptomatic and symptomatic gallstones in moderately obesewomen: a longitudineal follow-up study. American Journal of Gastroenterology, 1997. 92(1): p. 127-131.

114. Kono, S and Kochi S: Gallstones, serum lipids, and glucose tolerance among male officials of self-defense forces in Japan. Dig Dis Sci, 1988. 33(7): p. 839-834.

115. Dittrick, D and Thompson J: Gallbladder pathology in obesity. Obesity, 2005. 15(2): p. 238-242.

116. Sauter, GH, Thiessen K, Parhofer KG, et al.: Effects of ursodeoxycholic acid on cholesterol and bile acids in healthy subjects. Digestion, 2004. 70(2): p. 79-83.

117. Christensen, R, Astrup A, and Bliddal H: Weight loss: the treatment of choice for knee osteoarthritis? A randomized trial. Ostearthritis Cartilage, 2005. 13(1): p. 20-7.

118. Holmberg, S and Thelin N: Knee osteoarthritis and body mass index: a population based case control study. Scand J Rheumatology, 2005. 34(1): p. 59-64.

119. Linne, Y, Dye L, Barkeling B, et al.: Weight development over time in parous women-the SPAWN study-15 years follow up. Int J Obes Relat Metab Disorders, 2003. 27(12): p. 1516-22. 
120. Phillips, DIW, Bennett FI, Wilks R, et al.: Maternal body composition, offspring blood pressure and the hypothalmic-pituitaryadrenal axis. Pediatric and Perinatal Epidemiology, 2005. 19(4): p. 294-299.

121. Strohl, KP and Redline S: Recognition of obstructive sleep apnea. Ear Nose Throat, 1996. 154(2): p. 279-289.

122. Peppard, PE, Young T, Palta M, et al.: Longitudinal study of moderate weight change and sleep-disordered breathing. JAMA, 2000. 284(23): p. 3015-3021.

123. Strollo, PJ and Rogers RM: Ostructive sleep apnea. New England Journal of Medicine, 1996. 334(2): p. 99-104.

124. Speigel, K, Leproult R, L'Hermite-Baleriaux M, et al.: Leptin Levels are Dependent on Sleep Duration: Relationships with Sympathovagal Balance, Carbohydrate Regulation, Cortisol, and Thyrotropin. THe Journal of Clinical Endocrinology and Metabolism, 2004. 89(11): p. 5762-5771.

125. Piechota, G, Malkiewiez J, and Karwar ID: Obesity as a cause and result of disability. Prezegl Epidemiology, 2005. 59(155-161).

126. Poves, PI, Macias GJ, and Cebrara FMea: Quality of life in morbid obesity. Rev ESp Enferm Digest, 2005. 97(3): p. 187-195.

127. Daniels, SR: Regulation of body mass and management of childhood overweight. Pediatr Blood Cancer, 2005. 44(7): p. 589-94.

128. Williams AE, DB: A commercial weight-reducing organization: a critical analysis. Med J Aust, 1976. 1: p. 781-785.

129. Blackburn, GL and Waltman BA: Expanding the limits of treatment--new strategic initiatives. J Am Diet Assoc, 2005. 105(5 Suppl 1): p. S131-5.

130. Riebe, D, Greene GW, Ruggiero L, et al.: Evaluation of a healthy-lifestyle approach to weight management. Prev Med, 2003. 36(1): p. 45-54.

131. Wisotsky, W and Swencionis C: Cognitive-behavioral approaches in the management of obesity. Adolesc Med, 2003. 14(1): $p$. 37-48.

132. Poston, WS, Haddock, C.K., Dill, P.L., Thayer, B., \& Foreyt, J.P.: Lifestyle treatments in randomized clinical trials of pharmacotherapies for obesity. Obes Res, 2001. 9(9): p. 552-563.

133. Tsui, AGaW, Thomas A.: Systematic Review: An Evaluation of Major Commercial Weight Loss Programs in the United States. Annals of Internal Medicine, 2005. 142(1): p. 56-66.

134. Lowe MR, M-KK, Phelan S: Weight-loss maintenance in overweight individuals one to five years following successful completion of a commercial weight loss program. Int J Obes Relat Metab Disord, 2001. 25: p. 325-331.

135. Heshka S, GF, Anderson JW, Atkinson RL, Hill JO, Phinney SD, Miller-Kovach K, Pi-Sunyer FX: Self-help weight loss versus a structured commercial program after 26 weeks: a randomized controlled study. Am J Med, 2000. 109: p. 282-287.

136. Hamilton, M and Greenway F: Evaluating commercial weight loss programmes: an evolution in outcomes research. Obes Rev, 2004. 5(4): p. 217-32.

137. Wolfe, BL: Long-term maintenance following attainment of goal weight: a preliminary investigation. Addict Behav, 1992. 17(5): p. 469-77.

138. Atkins, R, Dr.Atkins' diet revolution: The high calorie way to stay thin forever. 1972, New York: David McKay, Inc.

139. Westman, EC, Yancy WS, Edman JS, et al.: Effect of 6-month adherence to a very low carbohydrate diet program. Am J Med, 2002. 113(1): p. 30-6.

140. Volek, J, Sharman, MJ, Gómez, AL, Judelson, DA, Rubin, MR, Watson, G, Sokmen, B, Silvestre, R, French, DN, and Kraemer, WJ: Comparison of energy-restricted very low-carbohydrate and low-fat diets on weight loss and body composition in overweight men and women. Nutr Metab (Lond), 2004. 1(13).

141. Willi, SM, Oexmann, Mary Joan, Wright, Nancy M., Collop, Nancy A and Key, L. Lyndon Jr: The Effects of a High-protein, Low-fat, Ketogenic Diet on Adolescents With Morbid Obesity: Body Composition, Blood Chemistries, and Sleep Abnormalities. Pediatrics, 1998. 101(1): p. 61-67.

142. Slavin, JL: Dietary fiber and body weight. Nutrition, 2004. 21(3): p. 411-418.

143. Warren, J and Henry JCea: Low glycemic index breakfasts and reduced food intake in preadolescent children. Pediatrics, 2003. 112: p. e414.

144. Kappagoda, C, Hyson, et al: Low-carbohydrate-high-protein diets: is there a place for them in clinical cardiology?" Journal of the American College of Cardiology, 2003. 43(5): p. 725-730.

145. Roberts, D: Quick weight loss: sorting fad from fact. The Medical Journal of Australia, 2001. 175: p. 637-640.

146. Anderson JW, KE, Jenkins DJ: Health advantages and disadvantages of weight reducing diets: a computer analysis and critical review. The Journal of the American College of Nutrition, 2000. 19(5): p. 578-590.

147. McMillan-Price, J and Brand-Miller J: Dietary approaches to overweight and obesity. Clin Dermatol, 2004. 22(4): p. 310-4.

148. Bouche, C, Rizkalla SW, Luo J, et al.: Five-week, low-glycemic index diet decreases total fat mass and improves plasma lipid profile in moderately overweight nondiabetic men. Diabetes Care, 2002. 25(5): p. 822-8.

149. Ebbeling, CB, Leidig MM, Sinclair KB, et al.: A reduced-glycemic load diet in the treatment of adolescent obesity. Arch Pediatr Adolesc Med, 2003. 157(8): p. 773-9.

150. Spieth, LE, Harnish JD, Lenders CM, et al.: A low-glycemic index diet in the treatment of pediatric obesity. Arch Pediatr Adolesc Med, 2000. 154(9): p. 947-51.

151. Wechsler, JG and Leopold K: Medical management of obesity. Langenbecks Arch Surg, 2003. 388(6): p. 369-74.

152. Fujioka, K: Management of obesity as a chronic disease: nonpharmacologic, pharmacologic, and surgical options. Obes Res, 2002. 10 Suppl 2: p. 116S-123S.

153. Wing, RR, Marcus MD, Salata R, et al.: Effects of a very-low-calorie diet on long-term glycemic control in obese type 2 diabetic subjects. Arch Intern Med, 1991. 151(7): p. 1334-40.

154. Willi, SM, Martin K, Datko FM, et al.: Treatment of type 2 diabetes in childhood using a very-low-calorie diet. Diabetes Care, 2004. 27(2): p. 348-53.

155. Armitage, CJ: Can the Theory of Planned Behavior Predict the Maintenance of Physical Activity? Health Psychology, 2005. 24(3): p. 235-245.

156. Epstein, LHV, Alice; Wing, Rena R.; McCurley, James: Ten-year outcomes of behavioral family-based treatment for childhood obesity. Health Psychology, 1994. Vol 13(5): p. 373-383. 
157. Wilson, GT: Behavioral treatment of childhood obesity: Theoretical and practical implications. Health Psychology, 1994. 13(1): p. 371-372.

158. Schmidt, M, Affenito SG, Striegel-Moore R, et al.: Fast-food intake and diet quality in black and white girls: the National Heart, Lung, and Blood Institute Growth and Health Study. Arch Pediatr Adolesc Med, 2005. 159(7): p. 626-31.

159. Affenito, SG, Thompson DR, Barton BA, et al.: Breakfast consumption by African-American and white adolescent girls correlates positively with calcium and fiber intake and negatively with body mass index. J Am Diet Assoc, 2005. 105(6): p. 93845.

160. Yanovski, SZ, R P Bain, and D F Williamson: Report of a National Institutes of Health-Centers for Disease Control and Prevention workshop on the feasibility of conducting a randomized clinical trial to estimate the long-term health effects of intentional weight loss in obese persons. Am J Clin Nutr, 1999. 69: p. 366-72.

161. Reeves, RS, McPherson RS, Nichaman MZ, et al.: Nutrient intake of obese female binge eaters. J Am Diet Assoc, 2001. 101(2): p. 209-15.

162. Yanovski, SZ and Devlin MJ: Role of behavioral therapy in the management of obesity. Endocr Pract, 1995. 1(5): p. 340-5.

163. Dubnov, G, Brzezinski A, and Berry EM: Weight control and the management of obesity after menopause: the role of physical activity. Maturitas, 2003. 44(2): p. 89-101.

164. Deedwania, PC and Volkova N: Current Treatment Options for the Metabolic Syndrome. Curr Treat Options Cardiovasc Med, 2005. 7(1): p. 61-74.

165. Chanoine, JP, Hampl S, Jensen C, et al.: Effect of orlistat on weight and body composition in obese adolescents: a randomized controlled trial. Jama, 2005. 293(23): p. 2873-83.

166. Boozer, CN, Daly PA, Homel P, et al.: Herbal ephedra/caffeine for weight loss: a 6-month randomized safety and efficacy trial. Int J Obes Relat Metab Disord, 2002. 26(5): p. 593-604.

167. Boozer, CN, Nasser JA, Heymsfield SB, et al.: An herbal supplement containing Ma Huang-Guarana for weight loss: a randomized, double-blind trial. Int J Obes Relat Metab Disord, 2001. 25(3): p. 316-24.

168. Greenway, FL, Ryan DH, Bray GA, et al.: Pharmaceutical cost savings of treating obesity with weight loss medications. Obes Res, 1999. 7(6): p. 523-31.

169. Molnar, D, Torok K, Erhardt E, et al.: Safety and efficacy of treatment with an ephedrine/caffeine mixture. The first double-blind placebo-controlled pilot study in adolescents. Int J Obes Relat Metab Disord, 2000. 24(12): p. 1573-8.

170. Kreider, R, Almada, AL, Antonio, J, Broeder, C, Conrad, E, Greenwood, M, Incledon T, Kalman, DS, Kleiner, SM, Leutholtz, B, Lowery, LM, Mendel, R, Stout, JR, Willoughby, DS, Ziegenfus, TN: ISSN Exercise \& Sport Nutrition Review: Research \& Recommendations. Sports Nutrition Review Journal, 2004. 1(1): p. 1-44.

171. Zemel, MB: Regulation of adiposity and obesity risk by dietary calcium: mechanisms and implications. J Am Coll Nutr, 2002. 21(2): p. 146S-151S.

172. Dulloo, AG, Seydoux J, Girardier L, et al.: Green tea and thermogenesis: interactions between catechin-polyphenols, caffeine and sympathetic activity. Int J Obes Relat Metab Disord, 2000. 24(2): p. 252-8.

173. Shigematsu, N, Asano R, Shimosaka M, et al.: Effect of administration with the extract of Gymnema sylvestre R. Br leaves on lipid metabolism in rats. Biol Pharm Bull, 2001. 24(6): p. 713-7.

174. Ishihara, K, Oyaizu S, Onuki K, et al.: Chronic (-)-hydroxycitrate administration spares carbohydrate utilization and promotes lipid oxidation during exercise in mice. J Nutr, 2000. 130(12): p. 2990-5.

175. Kriketos, AD, Thompson HR, Greene H, et al.: (-)-Hydroxycitric acid does not affect energy expenditure and substrate oxidation in adult males in a post-absorptive state. Int J Obes Relat Metab Disord, 1999. 23(8): p. 867-73.

176. Pariza, MW, Park Y, and Cook ME: Mechanisms of action of conjugated linoleic acid: evidence and speculation. Proc Soc Exp Biol Med, 2000. 223(1): p. 8-13.

177. Pariza, MW, Park Y, and Cook ME: The biologically active isomers of conjugated linoleic acid. Prog Lipid Res, 2001. 40(4): p. 283-98.

178. Zambell, KL, Keim NL, Van Loan MD, et al.: Conjugated linoleic acid supplementation in humans: effects on body composition and energy expenditure. Lipids, 2000. 35(7): p. 777-82.

179. Kreider, RB, Ferreira MP, Greenwood M, et al.: Effects of conjugated linoleic acid supplementation during resistance training on body composition, bone density, strength, and selected hematological markers. J Strength Cond Res, 2002. 16(3): p. 325-34.

180. Hasten, DL, Rome EP, Franks BD, et al.: Effects of chromium picolinate on beginning weight training students. Int J Sport Nutr, 1992. 2(4): p. 343-50.

181. Grant, KE, Chandler RM, Castle AL, et al.: Chromium and exercise training: effect on obese women. Med Sci Sports Exerc, 1997. 29(8): p. 992-8.

182. Walker, LS, Bemben MG, Bemben DA, et al.: Chromium picolinate effects on body composition and muscular performance in wrestlers. Med Sci Sports Exerc, 1998. 30(12): p. 1730-7.

183. Lukaski, HC, Bolonchuk WW, Siders WA, et al.: Chromium supplementation and resistance training: effects on body composition, strength, and trace element status of men. Am J Clin Nutr, 1996. 63(6): p. 954-65.

184. Phelan, S and Wadden TA: Combining Behavioral and Pharmacological Treatments for Obesity. Obesity Research, 2002. 10(6): p. 560-574.

185. Aronne, LJ: Modern medical management of obesity: the role of pharmaceutical intervention. Journal of the American Dietetic Association, 1998. 98(10): p. s23(4).

186. Berke, EM and Morden NE: Medical management of obesity. Am Fam Physician, 2000. 62(2): p. 419-26.

187. Moyers, SB: Medications as adjunct therapy for weight loss: approved and off-label agents in use. J Am Diet Assoc, 2005. 105(6): p. 948-59.

188. O'Brien, PE, Dixon JB, and Brown W: Obesity is a surgical disease: overview of obesity and bariatric surgery. ANZ J Surg, 2004. 74(4): p. 200-4.

189. Steinbrook, R: Surgery for severe obesity. N Engl J Med, 2004. 350(11): p. 1075-9.

190. Sugerman, HJ: Bariatric surgery for severe obesity. J Assoc Acad Minor Phys, 2001. 12(3): p. 129-36. 
191. Miller, WC, Koceja DM, and Hamilton EJ: A meta-analysis of the past 25 years of weight loss research using diet, exercise or diet plus exercise intervention. Int J Obes Relat Metab Disord, 1997. 21(10): p. 941-7.

192. Pikholz, C, Swinburn B, and Metcalf P: Under-reporting of energy intake in the 1997 National Nutrition Survey. N Z Med J, 2004. 117(1202): p. U1079.

193. Winkler, J: The fundamental flaw in obesity research. Obesity Reviews, 2005. 6(3).

194. Klesges, RC, Ward KD, Shelton ML, et al.: Changes in bone mineral content in male athletes. Mechanisms of action and intervention effects. Jama, 1996. 276(3): p. 226-30.

195. Van Loan, MD: Bioelectrical impedance analysis to determine fat-free mass, total body water and body fat. Sports Med, 1990. 10(4): p. 205-17.

196. Services, DoHaH: Long Term Weight Maintenance: Basic and Clinical Studies. http://grants.nih.gov/grants/guide/pa-files/PA04-092.html, 2004.

197. Antonio, J and Stout J, eds. Sports Supplements. 1st ed. 2001, Lippincott Williams \& Wilkins: Philadelphia, Pa.

198. Smith, NJ: Weight control in the athlete. Clin Sports Med, 1984. 3(3): p. 693-704.

199. Jonnalagadda, SS, Skinner R, and Moore L: Overweight athlete: fact or fiction? Curr Sports Med Rep, 2004. 3(4): p. 198-205.

200. Rankin, JW: Weight loss and gain in athletes. Curr Sports Med Rep, 2002. 1(4): p. 208-13.

201. Fogelholm, M: Effects of bodyweight reduction on sports performance. Sports Med, 1994. 18(4): p. 249-67.

202. Kleiner, S, Power Eating. 2nd ed. 2001, Champaign, IL: Human Kinetics. 282. 